\title{
Acidic Exo-polysaccharide produced from marine Bacillus sp. NRC5 to treat and protect chemical-induced mammary carcinomas in rats
}

Samah A. El-Newary ( $\square$ samahelnewary@yahoo.com )

Medicinal and Aromatic Plants Research Department National Research Center

Manal G. Mahmoud

National Research Centre

Mohsen Asker

National Research Centre

Eman R Youness

National Research Centre

Abeer Ibrahim

Medicinal and Aromatic Plants Research Department National Research Center

\section{Research Article}

Keywords: Marine Bacillus sp. NRC5, Acidic Exo-polysaccharide, breast cancer, 7,12-Dimethylebenz-(a)-anthracene, cancer growth rate-limiting enzymes, anti-inflammatory effect, antioxidant characters

Posted Date: February 23rd, 2022

DOI: https://doi.org/10.21203/rs.3.rs-1361975/v1

License: (c) (i) This work is licensed under a Creative Commons Attribution 4.0 International License. Read Full License 


\section{Abstract}

Background: Cancer is a leading cause of death worldwide, causing approximately ten million deaths in 2020. This investigation motivated us to study the prophylactic and therapeutic effect of acidic exopolysaccharide obtained from marine Bacillus sp. NRC5 (BEPS) in breast cancer. Methods: The anti-breast cancer efficacy of BEPS was proceeded in female Sprague-Dawley rats in the chemical-induction route. Mammary carcinoma was developed after five months using 7,12-Dimethylebenz-(a)-anthracene (DMBA in a single dose, $65 \mathrm{mg} / \mathrm{kg}$ in an intragastric route). Results: BEPS (200 mg/ kg orally) exhibited remarked protective and therapeutic effect, where it significantly reduced i) cancer growth rate-limiting enzymes; aromatase (51.14 and 77.31\%) and Na+/K+ ATPase (78.25 and 73.51\%) activities, ii) cyclooxygenase-2 (31.67 and 50.10\%) activity, iii) oxidative stress biomarker; malondialdehyde (88.26 and $88.18 \%$ ) level, iv) estrogen level (51.91 and 60.67\%), and carcinoembryonic antigen, CEA (36.7 and 35.14\%) compared to DMBA-group that elevated all determined parameters significantly $(P \leq 0.05)$. Conclusion: BEPS showed a promising anti-breast cancer impact with a reasonable safety margin. The result of BEPS may be related to its antioxidant \& anti-inflammatory characters and its inhibitory effect on aromatase and $\mathrm{Na}+/ \mathrm{K}+\mathrm{ATPase}$ activities, which is attributed to its unique composition containing sulfated groups and uronic acids.

\section{Introduction}

Breast cancer occurs when normal cells in breast tissue start to grow and divide in an out-of-control manner. Breast cancer often initiates in breast milk ducts called ductal cancers, accounting for about $80 \%$ of all breast cancers. Many risk factors are involved in breast cancer incidence, including aging, family history, heredity, dense breasts, and race. Breast cancer appeared with some symptoms like breast lump and pain, alteration in the breast size or shape, a dimpling, redness or a rash of the breast, flaky or crusty looking skin around the nipple, inward-turning nipple, nipple discharge ${ }^{1}$

Additionally, estrogen and progesterone are involved in the growth of some breast cancers. Therefore, breast cancer divides into hormone-sensitive (HR-positive) and hormone-insensitive (ER-negative). ER-negative is breast cancer does not depend on estrogen to proliferate, whereas ER-positive is the cancer cells that use estrogen to grow. Approximately $80 \%$ of breast cancers are ER-positive ${ }^{2}$.

Hormone therapy is the drug that can inhibit or avoid the progression of hormone-sensitive cancers by preventing the body's capability to produce estrogen and progesterone hormones or by interfering with these hormones' functions on breast cancer cells. Several strategies have been proved to manage ER-positive. The first strategy is blocking ovarian function through ovarian ablation or temporal suppression by gonadotropin-releasing hormone (GnRH) agonists drugs as luteinizing hormone-releasing hormone (LH-RH) agonists. The second and third strategies block estrogen production or functions by aromatase inhibitors (Als) or selective estrogen receptor modulators (SERMs) drugs ${ }^{3-4}$.

Als are drugs that can block aromatase enzyme activity to convert testosterone to estrogen. Anastrozole (Arimidex $\left.{ }^{\circledR}\right)$ and letrozole (Femara ${ }^{\circledR}$ ) are the approved Als drugs by the FDA for breast cancer management. They are approved for this use in postmenopausal women as initial therapy for metastatic or locally advanced ER-positive ${ }^{3-4}$. SERMs, such as Tamoxifen, suppressed estrogen function as a promoter of the proliferation of breast cancer cells. SERMs fasten to estrogen receptors instead of estrogen, leading to the prevention of estrogen function ${ }^{\mathbf{5}}$. The FDA has approved both Tamoxifen and Raloxifene to reduce the risk of developing breast cancer in women.

Unfortunately, hormone therapy has many side effects, including hot flashes, night sweats, vaginal dryness, and disruption in premenopausal women's menstrual cycle. In accordance, aromatase inhibitors drugs increase the risk of bone loss, mood swings, depression, loss of libido, heart attack, angina, heart failure, and hypercholesterolemia ${ }^{6-8}$. 
Based on the above, investigating another alternative approach for breast cancer protection and management from natural origin is essential.

In our previous study, acidic Exo-polysaccharide from marine Bacillus amyloliquefaciens 3MS 2017 was produced. It showed anti-breast cancer effects in DMBA-induced breast cancer rats, like hormone therapy (aromatase inhibitor and anti-estrogenic effect). These results encourage us to search for and produce more of polysaccharides from marine sources for this purpose. In 2021, we produced another polysaccharide from the marine source Bacillus sp. NRC5 (BEPS) is related to the Egyptian red sea ${ }^{9}$. BEPS was characterized by many active groups, including $\mathrm{OH}, \mathrm{C}^{-} \mathrm{H}, \mathrm{COO}^{-}$, $\mathrm{C}-\mathrm{O}-\mathrm{C}, \mathrm{S}=\mathrm{O}$, and $\mathrm{C}-\mathrm{O}-\mathrm{S}$ groups and low molecular weight and $\beta$-glycosidic linkage. BEPS consists of glucose, galactose, and mannouronic acid with a molar ratio of 1.0: 1.7: 0.8. In addition, BEPS exhibited in-vitro antioxidant, selective anti-inflammatory. In addition, BEPS caused potent anticancer activity against MCF-7 cells with $\mathrm{IC}_{50}$ and IC $\mathrm{IO}_{90}$; 76.70 and $133.50 \mathrm{mg} / \mathrm{mL}$, respectively. Additionally, BEPS occurred antitumor ability against Ehrlich Ascites Carcinoma in mice (EAC) regarding the increase in life span, hematological parameters modulation, and reduction in tumor volume and weight.

The current study aimed to investigate the possible use of BEPS in treating chemically-induced breast cancer in rats, based on its antioxidant, anti-inflammatory, and antitumor characters.

\section{Materials And Methods}

\section{Chemicals}

7, 12 di-methylbenze -anthracene (DMBA) was purchased from Sigma Aldrich, USA. Ethylenediamine tetraacetate (EDTA), Sodium dihydrogen phosphate, disodium monohydrogen phosphate were purchased from Fin Chem Ltd. Spectrophotometric Kits were purchased from Bio diagnostic, Egypt. ELISA kits for cyclooxygenases sub-unit determination (COX-1 and COX-2), aromatase, $\mathrm{Na}^{+} / \mathrm{K}^{+}$ATPase sub-unit assessment, carcinoembryonic antigen (CEA), estrogen, and progesterone quantities were purchased from Sunlong Biotech Co., LTD, PingShui Street, Gong Shu District, Hangzhou, Zhejiang, China, Email: Sales@Sunlongbiotech.Com.

\section{Production and isolation of EBPS from Bacillus sp. NRC5}

The strain was isolated from marine and was placed in the collection culture at the Microbial Biotechnology Department, National Research Centre, Dokki, Giza, Egypt. The production of exopolysaccharide (EPS) by Bacillus sp. NRC5 was performed by flask fermentation using Mohamed and colleagues' previously reported media and assay ${ }^{9}$.

\section{Animals}

Young virgin Sprague-Dawley female rats (one hundred female, 60 days old, and 100-130 g weight) were obtained from the animal house of the National Research Centre. Rats were kept under the laboratory facilities $\left(25 \pm 2^{\circ} \mathrm{C}\right.$, temperature 60-65\% humidity, and a 12-h light: 12-h dark cycle). Food was a chow-based diet obtained from the animal house. Food and water are ad libitum during the experimental period (8 months).

\section{Chemically induced mammary carcinomas in female rats}

According to Yerma et al. ${ }^{47}$, mammary carcinomas were established in Sprague-Dawley female rats. Rats have a single intragastric dose of DMBA dissolved in sesame oil ( $65 \mathrm{mg} / \mathrm{kg}$ body weight). After five months from DMBAadministration, the mammary carcinomas incidence was estimated through tumor biomarkers (CEA), cancer growthrate-limiting enzyme (aromatase), and clear notice of tumor (image 1). Animals that passed $400 \mu \mathrm{g} \mathrm{Eq} / \mathrm{mL}$ of CEA and 
$5.00 \mu \mathrm{g} \mathrm{Eq} / \mathrm{mL}$ of aromatase were considered breast cancer females, whereas negative control rats did not pass 250 and $0.8 \mu \mathrm{g} \mathrm{Eq} / \mathrm{mL}$ CEA and aromatase, respectively. Obtained data showed that about $80 \%$ of DMBA force-fed rats recorded a significant increase in considered biomarkers.

\section{Study plan work}

One hundred female rats were divided into three main groups: negative, cancer, and BEPS groups, as explained in Image 2.

The negative group was twenty-rat administrated normal saline for eight months and remained as ve- control.

The cancer group was twenty-rat were administrated one dose of DMBA (65mg/ kg body weight) intragastrically. They were remained under laboratory conditions for five months, followed by normal saline receiving for another three months. Thus, it was considered as DMBA-control.

The BEPS group contained sixty-rat that were divided into three subgroups, each twenty-rat, as follows;

1. Subgroup 1 was administrated normal saline for five months and then force-fed the BEPS at a dose of $200 \mathrm{mg} / \mathrm{kg}$ body weight/ day equal to the tenth of $\mathrm{LD}_{50}{ }^{9}$ for another three months. This subgroup is represented for studying the BEPS- sub-chronic toxicity performance.

2. Subgroup 2 first received the BEPS at a $200 \mathrm{mg} / \mathrm{kg} /$ day dose for three months, followed with oral administration of DMBA in one dose and kept under laboratory conditions for five months. Therefore, this subgroup is represented as a pre-treatment group.

3. Subgroup 3 was firstly administered one dose of DMBA and remained under laboratory conditions for five months. Then, they were orally received the BEPS at a dose of $200 \mathrm{mg} / \mathrm{kg} /$ day for three months. Therefore, this subgroup is represented as the post-treatment group.

The experimental period was continued to eight months, and then animals were fasted overnight. Fasted rats were injected with ketamine and xylazine ( 87 and $13 \mathrm{mg} / \mathrm{kg}$ of body weight, respectively), dissolved in normal saline for anesthesia 48 . The blood samples were collected from the retro-orbital plexus, and serum was obtained by centrifugation at $4000 \mathrm{~g}$ for $10 \mathrm{~min}$ using Sigma Laborzentrifugen (Osterode am Harz, Germany). Organs were collected, washed in ice saline, and were freshly weighted for chronic toxicity assessments.

The mammary tissue was excised, washed in ice-cold 1.15\% $\mathrm{NaCl}$ buffer solution, and blotted. The weight of the mammary tissue was determined and recorded. A portion of mammary tissue was homogenized in a phosphate buffer (50 mM, pH 6.8). The resulting mixture was spun at 10,000g for $15 \mathrm{~min}$ for biochemical analyses.

\section{Tumor volume and mass}

The rat breast tissue areas were palpated twice weekly to detect the appearance of breast tumor masses and monitor their progression. Once a mass in the breast pad was detected, its size and location were recorded. Tumor masses were examined, then excised, rinsed in phosphate-buffered saline (PBS), individually weighed, and measurement taken as per published protocol ${ }^{49}$.

\section{Biochemical analysis}

\section{Chronic toxicity parameters}


Liver function tests; total protein (TP) and albumin concentration, aspartate aminotransferase (AST), and alanine aminotransferase (ALT) activities were spectrophotometrically (Jasco, serial No. C317961148, Japan) assessed according to Henry ${ }^{50}$, Doumas et al..$^{51}$ and Reitman and Frankel ${ }^{52}$, respectively. Globulin was calculated as the difference between the total protein and albumin ${ }^{53}$. The kidney function, including urea, uric acid, and creatinine, were estimated spectrophotometrically according to Tabacco et al. ${ }^{54}$, Gochman and Schmitz ${ }^{55}$, and Faulkner and King ${ }^{56}$, respectively. Lipid profile, including total cholesterol (TC), high-density lipoprotein cholesterol (HDL-C), and triglycerides (TG), were spectrophotometrically assayed according to the methods of Allain et al. ${ }^{\mathbf{5 7}}$, Naito and Kaplan ${ }^{58}$, and Fossati and Prencipe ${ }^{59}$. Low-density lipoprotein cholesterol (LDL-C), very low-density lipoprotein cholesterol (VLDL-C), and the risk ratio were calculated based on Friedewald et al. ${ }^{60}$, Naito, and Kaplan ${ }^{58}$, and Kikuchi et al. ${ }^{61}$.

\section{Antioxidants biomarkers for tissue samples}

Glutathione (GSH) concentration or antioxidant enzymes activities; glutathione reductase (GR), glutathione S-transferase (GST), Glutathione peroxidase (GPx), catalase (CAT), and superoxide dismutase (SOD) were spectrophotometrically assayed as the methods of Griffith ${ }^{62}$, Goldberg and Spooner ${ }^{6]}$, Paglia and Valentine ${ }^{64}$, Habig et al. ${ }^{65}$, Beers and Sizer ${ }^{66}$, and Fridovich ${ }^{67}$, respectively.

Malondialdehyde (MDA), the oxidative stress biomarker, was spectrophotometrically determined in tissue samples using Ohkawa et al. ${ }^{68}$.

\section{Anti-inflammatory and cancer biomarkers}

COX-1 and COX-2, cancer growth rate-limiting enzymes sub-unites (aromatase and a1-Na/K ATPase) and tumor biomarker (CEA) and sexual hormones (estrogen and progesterone) were measured using ELISA kits of Sunlong Biotech Co., LTD.

\section{Histological investigations:}

Samples of all animals were dissected immediately after anesthesia. The specimens were then fixed in $10 \%$ neutralbuffered formalin saline for 24 hours. All the specimens were then dehydrated in ascending grades of alcohol, cleared in xylene, and embedded in paraffin wax. Serial sections of $6 \mu \mathrm{m}$ thick were cut and stained with hematoxylin and eosin for histopathological investigations. Images were captured and processed using Adobe Photoshop version $8.0{ }^{69}$.

\section{Statistical analysis}

The presented data are mean of 10 replicates \pm SD. Data were analyzed using ANOVA one-way and post hoc for multiple comparisons using the IBM-SPSS statistics program (version 25). $P \leq 0.05$ was considered as a significant difference.

\section{Results}

Impact of the BEPS administration on the chronic toxicity

The effect of BEPS administration on chronic toxicity during three months, including relative weight of vital organs, liver and renal functions, and lipid profile of breast cancer female rats shown in Table 1, 2, 3, and 4.

\section{Impact on the relative weight of vital organs}

Breast cancer incidence was accompanied with significant enlargement on liver, spleen, heart, and breast that reached $4.69 \pm 0.15,0.95 \pm 0.04,0.52 \pm 0.04$, and $10.56 \pm 0.46 \%$, respectively,relative to $100 \mathrm{~g}$ of total body weight in comparison 
with those of the negative group; $2.88 \pm 0.08,0.39 \pm 0.03,0.44 \pm 0.02$, and $2.27 \pm 0.22 \%$,respectively $(P \leq 0.05)$. On the contrary, it caused significant shrinkage on kidneys and lungs that reached $0.71 \pm 0.04$ and $0.66 \pm 0.02 \%$, sequentially, from total body weight, compared to corresponding values in the negative group; $1.01 \pm 0.02$ and $0.80 \pm 0.04 \%$, $(P \leq$ 0.05), Table (1).

Administration of BEPS before DMBA-induction in the post-treatment group succeeded in maintaining vital organs near to normal ranges. Where, relative weight of liver, spleen, heart, and breast were significantly reduced to 3.09 $\pm 0.18,0.74 \pm 0.05,0.39 \pm 0.02$., and $5.12 \pm 0.16 \%$, respectively, in comparison with the corresponding values in DMBAgroup; $4.69 \pm 0.15,0.95 \pm 0.04,0.52 \pm 0.04$, and $10.56 \pm 0.46 \%$, sequentially. In addition, shrank kidney and lung were significantly ameliorated towards normal range; $1.19 \pm 0.08$ and $0.72 \pm 0.02 \%$, respectively, compared to that of DMBAgroup ( $P \leq 0.05)$, Table (1).

The same trend was observed when female rats were force-fed DMBA firstly and then treated with BEPS for three months in the treating group. These rats restored the relative weight of vital organs in a healthy status. The relative weight of the liver, spleen, and breast was reduced to $3.45 \pm 0.13,0.76 \pm 0.03$, and $6.11 \pm 0.09 \%$, respectively, compared to those recorded in the DMBA- group. Meanwhile, kidney and lung were significantly enlarged to be $0.96 \pm 0.03$ and $0.75 \pm 003 \%$, respectively, compared to DMBA-group ( $P \leq 0.05)$, Table (1).

The relative weight of the brain did not significantly change by either DMBA or BEPS, compared to the negative group. Likewise, the relative weight of vital organs of the BEPS-group did not alter substantially compared to the negative group Table (1).

\section{Impact on liver functions}

Female rats force-fed DMBA suffered from hepatotoxicity causing a liver disturbance that represented as a remarkable leakage in AST and ALT enzymes into circulation (161.01 \pm 1.00 and $48.75 \pm 1.05 \mathrm{U} / \mathrm{L}$, respectively) in comparison with those of the negative group (69.45 \pm 2.90 and $26.89 \pm 0.91 \mathrm{U} / \mathrm{L}$, respectively). Total protein and its two fractions (albumin and globulin), and GSH concentration, were reduced to $3.37 \pm 0.16,2.18 \pm 0.15,1.19 \pm 0.04$, and 2.47 $\pm 0.24 \mathrm{mg} / \mathrm{dL}$, respectively, responding to DMBA administration, concerning that of the negative- group $(7.89 \pm 0.24,4.51$ $\pm 0.33,4.38 \pm 0.07$ and $7.24 \pm 0.11 \mathrm{mg} / \mathrm{dL}$, respectively) $(P \leq 0.05)$, Table (2).

The ameliorative effect of BEPS on the pre-treatment group represented maintaining liver performance within normal ranges. Liver AST and ALT remained near to the normal ranges. In addition, total protein and its two fractions, albumin and globulin, were restored within normal levels as compared to DMBA- group. In parallel, liver GSH level has remained close to normal compared to GSH of the DMBA-group.

Liver functions of post-treatment could return towards normalization in comparison with DMBA-group. The leakage of AST and ALT into circulation was reduced, and these enzymes were decreased significantly, concerning DMBA- group. In accordance, total protein, albumin, and globulin were significantly elevated compared to the DMBAgroup values. In addition, the GSH level was progressed considerably compared to DMBA-group.

The liver function and GSH concentration of the BEPS-group had an insignificant alteration compared to the negative group.

\section{Impact on kidney function}

According to the kidney function of the negative group, DMBA-group produced a significant increase in serum creatinine, urea, and uric acid to reach $4.06 \pm 0.16,12.43 \pm 0.47$, and $3.07 \pm 0.17 \mathrm{mg} / \mathrm{dL}$, respectively $(P \leq 0.05)$, Table (3). 
Serum urea concentration was significantly reduced in pre-treatment or post-treatment, compared to DMBAgroup. Urea of BEPS control showed a significant reduction, compared to the negative group. Serum uric acid concentration of rats administrated BEPS, whether before DMBA administration or after that, was significantly declined, compared to DMBA-group. An insignificant increment was recorded in uric acid of BEPS-control concerning the negative group. Serum creatinine concentration was depleted in the pre-treatment and post-treatment groups, compared to DMBA-group. BEPS-group appeared with a normal creatinine level compared to negative group value.

\section{Impact on lipid components properties}

DMBA force-feeding exhibited hyperlipidemia status concerning the negative control. Total cholesterol (TC), triglycerides (TG), very low-density lipoprotein-cholesterol (VLDL-C), and low-density lipoprotein-cholesterol (LDL-C) were significantly magnified to $161.01 \pm 5.89,184.45 \pm 1.28,32.20 \pm 1.18$, and $123.76 \pm 1.61 \mathrm{mg} / \mathrm{dL}$, respectively, compared to $86.59 \pm$ $3.16,66.89 \pm 2.47,17.12 \pm 0.63$, and $6.77 \pm 2.94 \mathrm{mg} / \mathrm{dL}$ in the negative control. Whereas high-density lipoprotein cholesterol (HDL-C) was significantly declined to $29.38 \pm 1.08 \mathrm{mg} / \mathrm{dL}$ in DMBA-group, compared to $43.00 \pm 2.54 \mathrm{mg} / \mathrm{dL}$ in the negative control ( $P \leq 0.05)$, Table (4).

BEPS co-administration protected pre-treated rats from hyperlipidemia and restored the lipid profile of these rats within normal ranges. However, the lipid profile of the post-treatment group, including TC, TG and VLDL-C, and LDL-C, were significantly depleted compared to DMBA-group. In addition, BEPS significantly progressed the HDL-C level of the post-treatment group compared to DMBA-group.

Concerning the post-treatment group, BEPS treatment returned its lipid profile toward normalization. Posttreatment rats' TC, TG, and VLDL-C, and LDL-C levels were remarkable compared to the DMBA-group. On the other hand, the HDL-C level of the post-treatment group was elevated over HDL-C of the DMBA-group. As a result, the lipid profile of the BEPS-group was within normal ranges of the negative group. Furthermore, increasing HDL-C and decreasing LDL-C significantly reduced the risk ratio of pre-treatment, post-treatment, and BEPS-group $(0.27 \pm 0.06,0.19$ \pm 0.03 , and $0.16 \pm 0.07 \%$, respectively) to be within normal ranges.

\section{Effect on lipid peroxidation biomarker (MDA)}

MDA level in tissue homogenate was significantly elevated due to DMBA administration, which increases lipid peroxidation. The MDA level of the DMBA-group was significantly magnified, compared to the negative control (24.70 \pm 1.50 and $2.12 \pm 0.09 \mathrm{mmol} / \mathrm{L}$, respectively) $(P \leq 0.05)$. Regarding pre-treatment and post-treatment groups, forcefed BEPS for three months, MDA level was significantly minimized to occur within normal ranges compared to DMBAgroup. There is an insignificant difference between the MDA of the BEPS-group and the negative group (Figure 1).

\section{Impact of BEPS on mammary tissue antioxidant status}

Antioxidant parameters of DMBA- group either non- enzymatic as GSH or enzymatic as GR, GST, GPx, CAT, and SOD were significantly diminished from $3.24 \pm 0.2 \mathrm{mg} / \mathrm{dL}, 3.99 \pm 0.24,3.57 \pm 0.25,1.63 \pm 0.24,19.10 \pm 1.55$, and $16.60 \pm$ $1.14 \mathrm{U} / \mathrm{mg}$ protein/ min, respectively, in the untreated group to $0.86 \pm 0.05 \mathrm{mg} / \mathrm{dL}$., $0.96 \pm 0.03,1.12 \pm 0.10,0.43 \pm 0.02$, $4.10 \pm 0.16$, and $9.63 \pm 0.35 \mathrm{U} / \mathrm{mg}$ protein/ min, respectively, in the DMBA-group $(P \leq 0.05)$, Figure. 2 .

BEPS exhibited antioxidant ability in DMBA- induced breast cancer in female rats via the amelioration in all previous imbalanced antioxidant parameters. GSH concentration recorded significant magnification either in pre-treatment or post-treatment groups to record $7.00 \pm 0.20$ and $6.49 \pm 0.33 \mathrm{mg} / \mathrm{dL}$, respectively, compared to DMBA-group $(0.86 \pm 0.05$ $\mathrm{mg} / \mathrm{dL})$. GSH concentration of BEPS-group rats recorded a significant increment more than negative-group by about $99.64 \%$. 
GR activity of pre-treatment and post-treatment was significantly maximized to $8.36 \pm 0.24$ and $8.00 \pm 0.20 \mathrm{U} / \mathrm{mg}$ protein/ min compared to DMBA-group. On the other hand, GR activity of BEPS-control was significantly induced to 7.99 $\pm 0.36 \mathrm{U} / \mathrm{mg}$ protein/ min, compared to the negative group; $3.99 \pm 0.24 \mathrm{U} / \mathrm{mg}$ protein/ $\mathrm{min}$.

GST activity was significantly increased in BEPS pre-treatment or post-treatment groups to $5.03 \pm 0.16$ and $5.51 \pm$ $0.20 \mathrm{U} / \mathrm{mg}$ protein/ min, concerning the DMBA- group. In addition, the GST activity of BEPS-control was significantly boosted compared to the untreated group.

GPx activity of pre-treatment or post-treatment groups appeared with significant increment $(3.53 \pm 0.24$ and $3.27 \pm$ $0.16 \mathrm{U} / \mathrm{mg}$ protein/ $\mathrm{min}$ ), compared to DMBA-group. GPx of BEPS-control was significantly augmented to $3.26 \pm 0.03$ $\mathrm{U} / \mathrm{mg}$ protein/ min, compared to the negative group.

CAT activity of pre-treatment and post-treatment groups was increased more than CAT of DMBA-group by about 5.06 and 5.15 folds, respectively $(P \leq 0.05)$. On the other hand, the CAT activity of BEPS-control rats did not significantly change compared to the negative group.

SOD activity was significantly elevated due to BEPS administration either in pre-treatment or in post-treatment groups (16.57 \pm 2.05 and $16.67 \pm 0.18 \mathrm{U} / \mathrm{mg}$ protein/ min, respectively), compared to DMBA-group.

\section{Impact of BEPS on inflammation biomarkers}

Inflammation statues that associated with DMBA force-feeding were elicited by the remarkable boost in COX-2 expression ( $326.00 \pm 4.08 \mathrm{ng} \mathrm{Eq/mL}$, with $+168.31 \%$ increase) and remarkable reduction on COX-1 expression (102.00 \pm 1.22 , with $-78.30 \%$ reduction) compared to the negative group $(121.50 \pm 2.45$ and $470.00 \pm 4.08 \mathrm{ng} \mathrm{Eq} / \mathrm{mL})(P \leq$ 0.05), (Figure 3).

BEPS exhibited selective anti-inflammatory activity that represented as a dramatic decrease in pro-inflammatory COX-2 expression synchronous with a significant increase in a constitutive COX-1 expression compared to the DMBA-group. As a result, COX-2 activity of pre-treatment or post-treatment groups was significantly reduced to $222.75 \pm 1.63$ and 162.67 $\pm 1.37 \mathrm{ng} \mathrm{Eq} / \mathrm{mL}$, with reduction percentages -31.67 and $-50.10 \%$,respectively, compared to DMBA-group.

Meanwhile, COX-1 activity was significantly augmented in pre-treatment or post-treatment groups to $180.00 \pm 2.45$ and $230.00 \pm 2.55 \mathrm{ng} \mathrm{Eq} / \mathrm{mL}$, respectively, increasing percentage +76.47 and $+125.59 \%$ more than COX- 1 of DMBA-group. On the other hand, COX-1 and COX-2 sub-unit in the BEPS-control group remained within normal levels, compared to the negative -group.

\section{Impact of BEPS on cancer growth rate-limiting enzymes}

\section{Aromatase activity}

DMBA-group rats produced aromatase higher than the negative group $(8.33 \pm 0.27$ and $0.80 \pm 0.02 \mu \mathrm{g} \mathrm{Eq} / \mathrm{mL})$. Force-feeding BEPS modulated aromatase expression of the pre-treatment group within the accepted range $(4.07 \pm 0.08$ $\mu \mathrm{g} \mathrm{Eq} / \mathrm{mL}$, with $-51.14 \%$ reduction), compared to DMBA-group $(P \leq 0.05)$. Also, aromatase expression of the posttreatment group was restored nearly to the normal range $(1.89 \pm 0.09 \mu \mathrm{g} \mathrm{Eq} / \mathrm{mL}$ with $-77.31 \%$ reduction), compared to DMBA-group. The aromatase level of the BEPS-control recorded an insignificant change compared to the negative group (Figure 4A).

\section{$\mathrm{Na}^{+} / \mathrm{K}^{+}$ATPase activity}


a1- $\mathrm{Na}^{+} / \mathrm{K}^{+}$ATPase subunits were significantly increased by DMBA force-feeding, where $\mathrm{Na}^{+} / \mathrm{K}^{+}$ATPase was elevated from $0.50 \pm 0.02 \mu \mathrm{g} \mathrm{Eq} / \mathrm{mL}$ in the negative-group to $5.70 \pm 0.29 \mu \mathrm{g} \mathrm{Eq} / \mathrm{mL}$ in the DMBA-group $(P \leq 0.05)$ (Figure 4B). A significant reduction in the activity of $\mathrm{Na}^{+} / \mathrm{K}^{+}$ATPase was recorded in the pre-treatment and post-treatment groups (1.24 \pm 0.08 and $1.51 \pm 0.12 \mu \mathrm{g} \mathrm{Eq} / \mathrm{mL}$, with a reduction percentage -78.25 and $-73.51 \%$, respectively), compared to DMBA-group. Importantly, an insignificant difference was noticed between $\mathrm{Na}^{+} / \mathrm{K}^{+} \mathrm{ATPase}$ of BEPS positive control and the negative control.

\section{Impact of BEPS on cancer biomarker, CEA}

DMBA administration significantly maximized CEA levels of DMBA-group by about two-fold $(P \leq 0.05)$, compared to the negative group (524.17 \pm 1.02 and $279.97 \pm 1.04 \mu \mathrm{g} \mathrm{Eq} / \mathrm{mL}$, respectively) (Figure 4C). CEA levels of pre-treatment and post-treatment groups significantly reduced by about 36.04 and $35.14 \%$ than CEA of DMBA-group $524.17 \pm 1.02 \mu \mathrm{g} \mathrm{Eq} /$ $\mathrm{mL}$. BEPS-group produced CEA close to that produced in the negative control.

\section{Impact of BEPS on female sex hormones}

DMBA-group recorded significant elevation in estrogen secretion concurrently with a significant reduction in progesterone secretion $(105.14 \pm 3.21$ and $2.45 \pm 0.18 \mathrm{ng} / \mathrm{mL}$, respectively), compared to the negative-group (28.35 \pm 1.35 and $8.95 \pm 0.88 \mathrm{ng} / \mathrm{mL}$, respectively) ( $P \leq 0.05$ ) (Figure 5). BEPS significantly decreased estrogen secretion in pretreatment and post-treatment groups (50.56 \pm 1.67 and $41.35 \pm 2.03 \mathrm{ng} / \mathrm{mL}$, reducing 51.91 and $60.67 \%$, respectively), compared to DMBA-group. On the contrary, BEPS significantly progressed progesterone secretion of pre-treatment and post-treatment groups ( $4.26 \pm 0.31$ and $6.28 \pm 0.44 \mathrm{ng} / \mathrm{mL}$, increasing percentage 73.88 and $156.33 \%$, respectively), compared to DMBA-group. BEPS-group recorded a non-significant reduction in estrogen concentration concurrent with non-significant induction in progesterone production compared to the negative group.

\section{Tumor volume and mass}

Recorded data in Table $\mathbf{5}$ show that BEPS administration for three months significantly reduced the number of

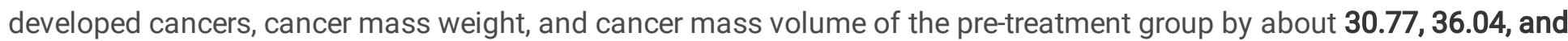
$35.94 \%$, respectively, compared to the DMBA-group ( $P \leq 0.05$ ). Additionally, the number of developed cancers, the weight of cancer mass, and volume of cancer mass were remarkably decreased from $13.00 \pm 0.98,1.11 \pm 0.12 \mathrm{~g}$, and $1.28 \pm$ $0.09 \mathrm{~cm}^{3}$ in the DMBA-group to $7.00 \pm 0.61,0.61 \pm 0.13 \mathrm{~g}$, and $0.60 \pm 0.08 \mathrm{~cm}^{3}$ in the pre-treatment group $(P \leq 0.05)$.

\section{Histological examination}

Data in Fig. 6 present the results of histopathology of the mammary glands sections of rats DMBA-induced breast cancer, and others treated BEPS for three months, compared to the negative control. Microphotograph using hematoxylin and eosin in control rats has appeared in sections. The negative control mammary section (A) showed rat mammary tissue in a typical arrangement of adipocytes (A) and duct (D) ( $\times 500)$. Mammary sections of BEPS-control rats (B) appear with normal breast parenchyma with no evidence of fibrocystic change, and any atypical features or carcinoma were noted in mammary glands of any animals.

Meanwhile, DMBA administration induced breast carcinoma in treated animals. The investigated sections showed well developed breast carcinoma with vast areas of necrosis and atypical proliferative changes shown in a progressive elongation of ducts and proliferation with the expansion of terminal lobular units and compression of surrounding fat pad, progressing to cystic papillary carcinoma. In addition, it is also shown that cell nucleomegaly, pleomorphism, increased mitosis, and moderate overall anaplasia. The mammary tissue section of DMBA treated group rat (C) showing dedifferentiated cells (DC) with the presence of mucin (M) in the ductal (D) lumen with discontinuous basement 
membrane ( $\times 500)$. Mammary tissue section of DMBA-treated group rat shows necrosis in vast areas, and tumor breakdown exhibits tumor cells in high proliferation, surrounded by residual viable proliferating malignant cells and dead cells, while the neoplastic cells invasive feature showed in bold blue (D).

On the contrary, the section of mammary tissue of the pre-treatment group (E) and the post-treated group rat $(\mathbf{F})$ appear near the normal control. Moreover, although the ducts (D) basement membrane is discontinuous, mucin and other foreign substances are absent. At the same time, it is covered with a thick mass of fibrous connective tissues with a post-treatment of polysaccharide, as shown in section $(F)(\times 500)$.

\section{Discussion}

In the present study, we studied the protective and therapeutic effect of acidic exopolysaccharide obtained from marine Bacillus sp. NRC5 (BEPS) in breast cancer. The model of this study was 7,12-Dimethylebenz-(a)-anthracene-induced mammary carcinoma in female rats. This model characterized by remarked alternations on safety profile, antioxidant defense system, inflammatory status, hormonal balance, and cancer growth rate-limiting enzymes; aromatase and $\mathrm{Na}^{+} / \mathrm{K}^{+}$ATPase activity. Interestingly, force-feeding BEPS for three months fixed all these harmful changes including, decreasing oxidative stress, reduction inflammation condition, amelioration the hormonal balance, and reducing aromatase and $\mathrm{Na}^{+} / \mathrm{K}^{+}$ATPase activity. Also, BEPS showed a potent safety margin. These previous improvements may be the reason for the protective and therapeutic effect of BEPS on DMBA-induced mammary carcinomas in rats.

Generally, DMBA force-feeding induced alternations in vital organs' relative weight, especially liver and breast, hepatotoxicity, nephrotoxicity, hyperlipidemia, and oxidative stress. The toxicity of DMBA recorded in the study agreed with Youness et al. ${ }^{10}$, Dakrory et al. ${ }^{11}$, Sharma et al. ${ }^{12}$, Nandhakumar et al. ${ }^{13}$, and El-Kholy et al. ${ }^{14}$, respectively. The mammary gland is one of the few organs that do not develop at birth. Therefore, DMBA has properties like that of estrogen ${ }^{15}$. In the breast, DMBA is converted to epoxides, active metabolites with a capacity for damaging DNA molecules, the main event in carcinogenesis initiation with the higher cellular proliferation index of type-1 and two lobules. Therefore, the relative weight of breasts was significantly elevated in DMBA-groups in this study and returned towards normalization when rats administrated BEPS. These results were agreed with Youness et al. ${ }^{10}$ and Ibrahim et al. ${ }^{16}$. The reduction in the relative weight of the breast may be associated with the anti-proliferative property of BEPS, where BEPS significantly decreased proliferation of the MCF7 cell line by about $65.20 \%$. Additionally, the antitumor activity of BEPS against tumor in EAC in mice model, where BEPS at a dose of $200 \mathrm{mg} / \mathrm{kg}$ significantly reduced tumor volume and weight ${ }^{9}$.

The susceptibility of the liver to damage is the greatest among other organs. DMBA is a polycyclic aromatic hydrocarbon metabolized in the liver, resulting in hepatotoxicity. That is represented as enlargement of the liver and disturbance in the functional and integrity of hepatic cells, resulting in leakage of liver enzymes into circulation (as an increment in AST and ALT in the blood). DMBA damages the susceptible amino acids of proteins, leading to decreased total proteins and its two fractions; albumin and globulin ${ }^{11}$. Protein production is an essential indicator of the seriousness of cellular dysfunction in the chronic hepatotoxicity associated with oxidative stress, where MDA was elevated in hepato-tissues. Progressed MDA level promoted lipid peroxidation of the cell membrane, leading to damage of these tissues ${ }^{14}$.

Also, DMBA promotes oxidative stress and ROS production, responsible for nephrotoxicity, hepatotoxicity, and neurotoxicity. Therefore, it could conclude that the liver and kidney disruption demonstrated in his study may be attributed to the oxidative stress induced by DMBA. We could conclude that the protective and therapeutic effect of BEPS on liver and kidney may be due to its antioxidant activities demonstrated in-vitro and in-vivo. Our previous study 
on BEPS showed antioxidant activities, including inhibiting lipid peroxidation that prevented MDA production in mammary cells and protected liver and kidney cells' function and integrity ${ }^{14}$. In addition, BEPS appeared ROS scavenging $\left(\mathrm{O}_{2}{ }^{-}, \mathrm{H}_{2} \mathrm{O}_{2}\right.$, and $\mathrm{NO}$ radicals) abilities, leading to reduced oxidative stress and consequent damages ${ }^{9}$. BEPS exhibited in-vivo antioxidants in this study, representing significant elevation on GSH concentration and significant activation on GR, GST, GPx, CAT, and SOD.

The depletion on GSH level and GR, GST, GPx, CAT, and SOD activities in the current study could explain through the effect of DMBA metabolites peroxide, which increased lipid peroxidation and blocked antioxidant enzymes (GR, GST, GPx, CAT, and SOD) ${ }^{17}$. MDA, the end product of lipid peroxidation, has a destructive capacity in the cellular antioxidant enzyme system and decreases the ability of the cell to prevent the generation of more ROS and free radicals ${ }^{18}$. BEPS activated antioxidant enzymes, which may decrease MDA concentration with an increase in GSH level as recorded in this study. GSH and related enzymes (GR, GST, and GPx) can keep cell integrity, protect the structure and function of cells, capture free radicals that damage cell membrane, and prevent ROS generation ${ }^{19}$.

The anti-inflammatory effect that showed after force-feeding the BEPS for three month was discussed below. The antiinflammatory effect was agreed with the results of Mahmoud et al. ${ }^{20}$. They found that exo-polysaccharide produced by Paenibacillus lactes NRC1 had anti-inflammatory activity on the carrageenan-induced paw edema in rats. Additionally, Ibrahim et al. ${ }^{16}$ reported that exo-polysaccharide produced from marine bacteria (Bacillus amyloliquefaciens 3MS 2017) exhibited a selective anti-inflammatory effect against COX-2 on DMBA- induced breast cancer female rats. The elevation in COX-2 expression is attributed to induction in iNOS levels in endothelial cells, which produce NO in the tissue. NO in the normal range is considered an anti-inflammatory agent, but it converted to pro-inflammatory with over-generation as it becomes an oxidative stress marker ${ }^{21}$. Therefore, components that decreased oxidative stress, ROS, and NO production can suppress COX-2 expression. Our previous study ${ }^{9}$ demonstrated that BEPS exhibited strong NO scavenging capacity with small $\mathrm{IC}_{50} ; 14.65 \mu \mathrm{g} / \mathrm{mL}$. In addition, COX-2 expression strongly affected ROS through promoting NF-kB and ERK1/2 in macrophages ${ }^{22}$. Thus, the selective anti-inflammatory of BEPS could be related to its antioxidant properties demonstrated in this study.

The anti-aromatase effect that showed after force-feeding the BEPS for three month is agreed with Chen et al. ${ }^{23}$, who reported that polysaccharides of white button mushrooms (Agaricus bisporus) were aromatase inhibitors in in-vitro and in-vivo models. Besides, polysaccharides inhibit aromatase activity in microsomes isolated from the human placenta. Aromatase, cytochrome P450, CYP19, is the enzyme that converts androgen hormone to estrogen. There is a direct correlation between COX-2 expression and aromatase expression in breast cancer cells. COX-2 produces prostaglandins2, interleukin-6, and TNF-a that drive aromatase activity. In addition, prostaglandin E-2 promotes aromatase expression via increase cyclic adenosine monophosphate (cAMP). Therefore, non-steroid and selective anti-inflammatory drugs are used in treating breast cancer to decrease aromatase expression by decreasing COX-2 production ${ }^{24}$. The reduction in aromatase expression in this study may be correlated to a decrease in COX-2 production recorded in the pre-treatment and post-treatment groups where COX-2 reduced by about 31.67 and $50.10 \%$, respectively, for the two treated groups (Figure 3).

BEPS inhibited $\mathrm{Na}^{+} / \mathrm{K}^{+}$ATPase, which significantly activated by DMBA. These results are agreed with Vanitha et al. ${ }^{18}$, where DMBA significantly increased membrane-bound enzymes' activities $\left(\mathrm{Na}^{+} / \mathrm{K}^{+} \mathrm{ATPase}, \mathrm{Ca}^{2+}\right.$ ATPase, and $\mathrm{Mg}^{2+}$ ATPase) of breast cancer rats. Meanwhile, Taurine treatment (100 mg/ kg) significantly ameliorated them. Khajah et al. ${ }^{25}$ documented that $\mathrm{Na}^{+} / \mathrm{K}^{+}$ATPase pump was inhibited by Ouabain and 3,4,5,6-tetrahydroxyxanthone (TTX) treatment in estrogen receptor-positive and negative breast cancer cells. The activation in $\mathrm{Na}^{+} / \mathrm{K}^{+}-\mathrm{ATP}$ ase by DMBA administration may be due to lipid peroxidation, which significantly increased in the current study ${ }^{18}$. On the contrary, 
BEPS suppressed $\mathrm{Na}^{+} / \mathrm{K}^{+}$ATPase activity in pre-treatment and post-treatment groups, related to its antioxidant properties. Hence, $\mathrm{NO}$ induces $\mathrm{Na}^{+} / \mathrm{K}^{+}$ATPase function in corpus cavernosum smooth muscle. Also, NO regulates the $\mathrm{Na}^{+} / \mathrm{K}^{+}$ATPase activity in-vitro, where the application of NO donors stimulates the vascular sodium pump. In addition, the elevated amount of NOcan also protect the $\mathrm{Na}^{+} / \mathrm{K}^{+}$ATPase activity against exogenous ${ }^{\circ} \mathrm{OH}$ induced inactivation ${ }^{26}$, ${ }^{18}$. BEPS showed NO scavenger capability $\left(\mathrm{IC}_{50} ; 14.65 \mu \mathrm{g} / \mathrm{ml}\right)$ and lipid peroxidation inhibition effect ${ }^{9}$.

BEPS caused remarked reduction on CEA concentration of breast cancer rats. These results are in agreement with Hamdy et al. ${ }^{27}$ and Mani et al. ${ }^{28}$, all of them found a significant increment in CEA of DMBA-induced breast cancer rats and a significant reduction after treatments with genistein, selenium, and their combination ${ }^{27}$ and naringin ${ }^{28}$. The high production of CEA is stopped before birth. However, some cancers as breast cancer, highly produce serum CEA, so it is considered a tumor marker of breast carcinoma ${ }^{29}$. Therefore, the increase of CEA on the DMBA-group may be correlated to cancer proliferation. Additionally, the decrease in CEA of BEPS-treated groups may be associated with its antiproliferative effect, demonstrated in our previous study ${ }^{9}$. BEPS showed anticancer effects against MCF-7 with IC 50 and $\mathrm{IC}_{90} ; 76.70$ and $133.50 \mathrm{mg} / \mathrm{ml}$, respectively.

BEPS reduced estrogen level of breast cancer rats, which increased significantly after DMBA force-feeding. These results agreed with Amin ${ }^{30}$, who reported that DMBA-induced mammary tumors secreted more estrogen. Meanwhile, the administration of water extract of chlorella significantly decreased it. Aromatase, called estrogen syntheses, is the key step in estrogen synthesis from androgen through the androgen aromatization process. Therefore, aromatase inhibition blocks the estrogen production mimic in postmenopausal women ${ }^{31}$. BEPS significantly reduced aromatase by about 51.14 and $77.31 \%$ on pre-treatment and post-treatment groups, compared to DMBA-group.

In parallel, the increase in progesterone recorded in the study could be discussed through the significant elevation recorded in SOD activity. Miyazaki et al. ${ }^{32}$ reported a significant increase in progesterone production by the in-vitro perfused rabbit ovary treated with SOD enzyme. They explained this increase because SOD may protect steroidproducing cells from damage due to the second generation of $\mathrm{OH}$ from $\mathrm{O}_{2}$ and $\mathrm{H}_{2} \mathrm{O}_{2}$. BEPS significantly elevated SOD activity by about 72.07 and $73.10 \%$ on pre-treatment and post-treatment groups, concerning the DMBA-group.

Finally, it is evident from obtained results of the current study that produced exopolysaccharide from Bacillus sp. NRC5 (BEPS) can protect and treat DMBA induced-mammary carcinomas in Sprague-Dawley female rats with a reasonable margin of safety. The sixth possible different hypothesis may be the anti-breast cancer mechanisms of BEPS.

The first hypothesis was the antioxidant capacity of BESP that presented as a significant rise in GSH and antioxidant enzymes (GR, GS, GPx, CAT, and SOD). ROS has a vital role in the cell cycle, where re-entry from G0 and the G2/M phase requires the highest amount of ROS among other phases, whereas the over-production of ROS has harmful effects on the cell ${ }^{33}$. Various cancer types as breast cancer are described as ROS- induced DNA damage. Oxidative stress has a vital role in cancer, including initiation, propagation, proliferation, migration, and angiogenesis metastasis, leading to advanced cancer. ROS induces cancer metastasis through interference in the cytoskeleton and extracellular matrix pathways. Furthermore, ROS can support the angiogenesis process, where the most proteins of angiogenesis as vascular endothelial growth factor (VEGF), fibroblast growth factor (FGF), and transcription factor HIF-1a are dependent on ROS release ${ }^{34}$. Therefore, it could be concluded that BEPS scavenged ROS in in-vitro ${ }^{9}$. Furthermore, BEPS activated antioxidant enzymes (GR, GST, GPx, CAT, and SOD) and increased GSH concentration in the current in-vivo study can participate in cancer protection and treatment through the antioxidant process.

The second hypothesis was its selective anti-inflammatory character of BEPS against COX-2, which is exhibited in this study. COX-2 involves in breast cancer, where a large amount of COX-2 is found in the tumor epithelium cells and a 
negligible amount in the epithelium healthy breast cell. About $40 \%$ of metastatic breast cancer has progressed COX-2 expression ${ }^{35}$. In experimental animals, genetic ablation of COX-2 reduces breast cancer incidence. Additionally, COX inhibitors, either NSAIDs or COXibs, can reduce chemically-induced breast cancer incidence and decrease implanted tumors' growth rate ${ }^{36}$. Furthermore, COX-2 can promote angiogenesis that is confirmed by the increased microvessel density and expression of proangiogenic genes, including VEGF, Ang1, and Flk-1 \& Flt-1. Meanwhile, COX-2 null mammary tissue has low proangiogenic gene expression. In parallel, COX-2 in transgenic animals showed a significant decrease in apoptosis. Moreover, COX-2 increases aromatase activity and expression by increasing cAMP ${ }^{37}$. Aromatase converts the androgen hormone to estrogen, strongly associated with breast cancer, where $60-70 \%$ of breast cancer are hormone-dependent. Finally, COX-2 works as an oncogene, angiogenesis promoter, apoptosis inhibitor, and aromatase activator. These encourage breast cancer formation ${ }^{38}$. Therefore, BEPS treated DMBA-induced breast cancer in this study through its selective COX-2 inhibitory action demonstrated in this in-vivo study and our previous in-vitro of

\section{Mohamed et al., ${ }^{9}$.}

The third hypothesis was the aromatase inhibitory property of BEPS demonstrated in the current study. Aromatase, cytochrome P450, CYP19 is the enzyme that converts androgen hormone to estrogen. Aromatase finds in many tissues, including breast and breast cancer tissue. Aromatase expressed in breast cancer tissue is higher than normal tissue by about 20 -fold ${ }^{39}$. Therefore, when aromatase activity is inhibited, estrogen production is reduced, leading to suppression of the devolving and progression of hormone-positive breast cancer 40 .

The fourth hypothesis is the $\mathrm{Na}^{+} / \mathrm{K}^{+}$ATPase suppression character of BEPS reported in the present study. The migration of cancerous cells needs adhesion complexes between migrating cells and surrounding extracellular matrix (ECM) proteins ${ }^{41}$. Migration and adhesion include continuous modification of cell motion, shape, and volume, where ion channels and pumps work their essential function. For example, $\mathrm{Na}^{+} / \mathrm{K}^{+}$-ATPase is involved in all cancer phases' initiation, propagation, and invasion. Hence, inhibition of $\mathrm{Na}^{+} / \mathrm{K}^{+}$ATPase impedes cancer cell proliferation and induces apoptosis. Additionally, suppression of $\mathrm{Na}^{+} / \mathrm{K}^{+}$-ATPase activates $\mathrm{Na}^{+}-\mathrm{Ca}^{2+}$ exchanger, where intracellular $\mathrm{Na}^{+}$is elevated, and intracellular $\mathrm{K}^{+}$is diminished, leading to a remarkable rise in intracellular $\mathrm{Ca}^{2+}{ }^{42}$. Furthermore, the cytosolic $\mathrm{Ca}^{2+}$ participates in the organization of apoptotic cells ${ }^{43}$. Also, suppression of $\mathrm{Na}^{+} / \mathrm{K}^{+}$ATPase suppresses cellular Src and Non-receptor protein kinases FAK activity that encourages the epithelial cell to proliferate, migrate, invade another place, and form a new blood vessel through activation VEGF synthesis ${ }^{41}$.

The fifth hypothesis was the anti-estrogenic effect of BEPS recorded in the current study. Women with androgens of blood higher-than-normal levels can directly be converted by aromatase to the estrogens, estrone, and estradiol, increasing the relative risk of breast cancer ${ }^{44}$. This evidence shows that if a woman is exposed to increased estrogen throughout her life, she is considered more at risk of breast cancer. In addition, the treatment of experimental animals by estrogen causes the development of mammary tumors. Together, these observations support the hypothesis that estrogen is a mammary-gland carcinogen. Estrogens contribute to each phase of the carcinogenic process (initiation, promotion, and progression) ${ }^{45}$.

The sixth hypothesis was the progesterone inducer effect of BEPS recorded in this study. Low progesterone receptors activate growth factor signaling and aggressive tumors. Liu et al. ${ }^{46}$ provide strong evidence that progesterone receptors status is an independent factor associated with improved survival in breast cancer patients. Therefore, assessment of progesterone receptors status, using the 1E2 rabbit monoclonal antibody and a 1\% cutoff for positive cells, has significant additional value in predicting patient survival and determining hormone therapy strategies beyond that obtained by estrogen receptor alone. 


\section{Conclusion}

Acidic exo-polysaccharide tested in the current study is produced from marine Bacillus sp. NRC5 (BEPS). BEPS appeared in-vitro anticancer character against MCF-7 in our previous study. The present study showed significant anti-breast cancer efficacy as a protective or therapeutic material in rats' DMBA-induced mammary carcinomas. In addition, BEPS down-regulated many pathways demonstrated as proliferation promoters, including oxidative stress, COX-2 overexpression, aromatase, $\mathrm{Na}+/ \mathrm{K}+$ ATPase, and estrogen secretion.

Additionally, BEPS promoted many pathways that have been reported as apoptosis inducers, including antioxidant defense system, COX-1 expression, and progesterone secretion. During the three-month follow-up, BEPS appeared a good margin of safety. Therefore, we recommended incorporating BEPS in an advanced clinical trial to be considered a novel therapy in breast cancer treatment presented from natural economic origin.

\section{Declarations}

\section{Ethical issues}

All experimental protocols and methods were approved by ethical guidelines (Ethical Committee for Animal Care and Use, Egypt). In addition, the study protocol was approved by the Medical Research Ethics Committee of the National Research Centre in Egypt under registration No 19/295 in 2019 and all of them were performed in accordance ARRIVE guidelines.

\section{Consent for publication}

Not applicable

\section{Availability of data and materials}

All data generated or analyzed during this study are included in this published article.

\section{Competing interests}

The authors declare that they have no conflict of Competing interests.

\section{Funding}

National Research Institute fund this research work within their ordinary research budgets. No other funding was received from any other party that may affect the results, either directly or indirectly.

\section{Authors Contributions}

MGM and MSA prepared the tested polysaccharide. AYI, ERY, and SAE performed animal experiments and biochemical assessments. In addition, AYI and SAE have participated in data analysis. All authors have accepted the final manuscript.

\section{Acknowledgments}

The authors would like to sincerely thank National Research Centre, Egypt, for funding this research work within the budget of project No 12060108 under the title "Discovery of new pharmaceutical raw material for treating prostate diseases." 


\section{References}

1. American Cancer Society. Cancer Facts \& Figures 2021. Cancer Facts \& Figures is an annual publication of the American Cancer Society, Atlanta, Georgia (2021)

2. Kohler, B. A., Sherman, R. L., Howlader, N., Jemal, A., Ryerson, A. B. \& Henry, K. A. Annual Report to the Nation on the Status of Cancer, 1975-2011, featuring incidence of breast cancer subtypes by race/ethnicity, poverty, and state. JNCl. J. Natl. Cancerlnst. 107, djv048. (2015)

3. Howell, A., Pippen, J., Elledge, R. M., Mauriac, L., Vergote, I. \& Jones, S. E. Fulvestrant versus anastrozole for the treatment of advanced breast carcinoma: a prospectively planned combined survival analysis of two multicenter trials. Cancer104, 236- 239 (2005).

4. Cuzick, J., Sestak, I., Baum, M., Buzdar, A., Howell, A. \& Dowsett, M. Effect of anastrozole and tamoxifen as adjuvant treatment for early-stage breast cancer: 10-year analysis of the ATAC trial. Lancet Oncol. 11, 1135- 1141 (2010).

5. Coombes,R. C., Kilburn, L. S., Snowdon, C. F., Paridaens, R., Coleman, R. E. \& Jones, S. E. Survival and safety of exemestane versus tamoxifen after 2-3 years' tamoxifen treatment (Intergroup Exemestane Study): a randomized controlled trial. Lancet 369, 559- 570 (2007).

6. Amir, E., Seruga, B., Niraula, S., Carlsson, L. \& Ocaña, A. Toxicity of adjuvant endocrine therapy in postmenopausal breast cancer patients: a systematic review and meta-analysis. J.Natl. Cancer Inst. 103, 1299- 1309 (2011).

7. Keshaviah, A., Dellapasqua, S., Rotmensz, N., Lindtner, J., Crivellari, D. \& Collins, J. CA15-3 and alkaline phosphatase as predictors for breast cancer recurrence: a combined analysis of seven international breast cancer study group trials. Ann. Oncol. 18, 701- 708 (2007).

8. Boccardo, F., Rubagotti, A., Guglielmini, P., Fini, A., Paladini, G. \& Mesiti, M. Switching to anastrozole versus continued tamoxifen treatment of early breast cancer. Updated results of the Italian Tamoxifen Anastrozole (ITA) Trial. Ann. Oncol. 17, vii10- vii14 (2006).

9. Mohamed, S. S., Ibrahim, A. Y., Asker, M. S., Mahmoud, M. G. \& El-Newary, S. A. Production, structural and biochemical characterization relevant to antitumor property of acidic exopolysaccharide produced from Bacillus sp. NRC5. Arch. Microbiol. 203, 4337- 4350 (2021).

10. Youness, E. R., Ibrahim, A. Y., El-Newary, S. A., Ibrahim, A. M. M. \& El Kashak, WA. Modulatory effect of Brassica oleracea L. var. italic extract in chemically induced mammary carcinomas in rats. Biosci. Res. 14, 331-346 (2017).

11. Dakrory, A. I, Fahmy, S. R, Soliman, A. M, Mohamed, A. S. \& Amer, S. A. M. Prophylactic and curative effects of the sea cucumber holothuria atra extract against DMBA-induced hepatorenal diseases in rats. BioMed. Res. Int. 2015, 563652 (2015).

12. Sharma, V., Paliwal, R., Janmeda, P. \& Sharma, S. H. The reno-prophylactic efficacy of Moringa oleifera pods on xenobiotic enzymes and antioxidant status against 7,12-dimethylbenz[a]anthracene exposed mice. J. Chin. Integr. Med. 10, 1171- 1178 (2012).

13. Nandhakumar, E., Purushothaman, A. \& Sachdanandam, P. Prophylactic effect of Shemamruthaa on lipids anomalies in 7,12-dimethylbenz[a]anthracene (DMBA)induced mammary carcinoma-bearing rats. Med. Chem. Res. 23, 3491- 3502 (2014).

14. El-Kholy, W., Serag, H., Zakaria, A. \& El Metwaly, A. The potency of some natural products on dimethyl benz(A) anthracene (DMBA) induced hepatotoxicity in rats. Egypt. J. Hosp. Med. 53, 1036- 1048 (2013). 
15. Wibowo, A. E., Sriningsih, Wuyung, P. E. \& Ranasasmita, R. The influence of DMBA (7,12-dimethylbenz[a]anthracene) regimen in the development of mammae carcinogénesis on Sprague Dawley female rat. Indonesian J. Cancer Chemopreve. 1, 60- 66 (2010).

16. Ibrahim, A. Y., Youness, E. R., Mahmoud, M. G., Asker, M. S. \& El-Newary, S. A. Acidic exopolysaccharide produced from marine Bacillus amyloliquefaciens 3MS 2017 for the protection and treatment of breast cancer. Breast Cancer: Basic and Clinical Research. 14, 1- 14 (2020).

17. Kumar, R., Kaur, R., Singh, A. P. \& Arora, S. Diminution of hepatic response to 7, 12-dimethylbenz( $a$ )anthracene by ethyl acetate fraction of Acacia catechu Willd. through modulation of xenobiotic. PLOS ONE. 9, e90083 (2014).

18. Vanitha, M. K., Baskaran, K., Periyasamy, K., Selvaraj, S., Ilakkia,

19. A. \& Saravanan, D. Effect of taurine on 7,12-dimethylbenz(a)anthracene-induced alterations in detoxification enzyme system, membrane bound enzymes, glycoprotein profile and proliferative cell nuclear antigen in rat breast tissue. J. Biochem. Mol. Toxicol. 30, 8 pages (2016).

20. Pushpakiran, G., Mahalakshmi, K. \& Anuradha, C. V. Taurine restores ethanol-induced depletion of antioxidants and attenuates oxidative stress in rat tissues. Amino Acids. 27, 91- 96 (2004).

21. Mahmoud, M. G., Mohamed, S. S.., Ibrahim, A. Y., El Awady, M. E. \& Youness, E. R. Exo-plysaccharide produced by Paenibacillus lactes

22. NRC1: its characterization and anti-inflammatory activity via cyclooxygenases inhibitory activity and modulation of inflammation related cytokines. Der Pharma Chemica. 8,16- 26 (2016).

23. Bogdan, C., Rollinghoff, M. \& Diefenbach, A. Reactive oxygen and reactive nitrogen intermediates in innate and specific immunity. Curr. Opin. Immunol. 12, 64- 76 (2000).

24. Barbieri, S. S., Eligini, S., Brambilla, M., Tremoli, E. \& Colli, S. Reactive oxygen species mediate cyclooxygenase-2 induction during monocyte to macrophage differentiation: critical role of NADPH oxidase. Cardiovasc. Res. 60, 187197 (2003).

25. Chen, S., Oh, S-R., Phung, S., Hur, G., Ye J. J. \& Kwok, S. L. Anti-aromatase activity of phytochemicals in white button mushrooms (Agaricus bisporus)

Cancer Res. 66, 12026- 12034 (2006).

26. Davies, G., Martin, L-A., Sacks, N. \& Dowsett, M. Cyclooxygenase-2 (COX-2), aromatase, and breast cancer: a possible role for COX-2 inhibitors in breast cancer chemoprevention. Ann. Oncol. 13, 669- 678 (2002).

27. Khajah, M. A., Mathew, P. M. \& Luqmani, Y. A. Na ${ }^{+} / \mathrm{K}^{+}$ATPase activity promotes invasion of endocrine resistant breast cancer cells. PLOS ONE. 13, e0193779 (2018).

28. Gupta, S., Moreland, R. B., Munarriz, R., Daley, J., Goldstein, I. \& Tejada, I. S. Possible role of $\mathrm{Na}^{+} / \mathrm{K}^{+}$-ATPase in the regulation of human corpus cavernosum smooth muscle contractility by nitric oxide. Br. J. Pharmacol. 116, 22012206 (1995).

29. Hamdy, S. M., Abdel Latif, A-K. M., Drees, E. A. \& Soliman, S. M. Prevention of rat breast cancer by genistin and selenium. Toxicol. Ind. Health. 28, 746- 757 (2012).

30. Mani, G., Arumugam, M., Mari, A. \& Devaki, T. Naringin attenuates DMBA-induced mammary carcinogenesis in rats via regulating the oxidative stress and antioxidants status. J. Chem. Pharm. Res. 10, 44- 54 (2018).

31. Faridi, S. H., Khan, M. A., Siddiqui, B., Maheshwari, V. \& Aggarwal, T. Role of serum carcinoembryonic antigen (CEA) as a tumor marker in breast cancer. Int. J. Adv. Med. Health Res. 1, 57-60 (2015).

32. Amin, A. Protective effect of green algae against 7, 12 di-methylbenze -anthracene (DMBA)-induced breast cancer in rats. Int. J. Cancer Res. 5, 12- 24 (2014).

Page $16 / 27$ 
33. Burstein, H. J., Prestrud, A. A., Seidenfeld, J., Anderson, H., Buchholz, T. A. \& Davidson, N. E. American society of clinical oncology clinical practice

guideline: update on adjuvant endocrine therapy for women with hormone receptor-positive breast cancer. J. Clin.

Oncol. 28, 3784- 3796 (2010).

34. Miyazaki, T., Sueoka, K., Dharmarajan, A. M., Atlas, S. J., Bulkley, G. B. \& Wallach, E. E. Effect of inhibition of oxygenfree radical on ovulation and progesterone production by the in-vitro perfused rabbit ovary. J. Reprod. Fertil. 91, 207212 (1991).

35. Havens, C. G., Ho, A., Yoshioka, N. \& Dowdy, S. F. Regulation of late G1/S

Phase transition and APCCdh1 by reactive oxygen species. Mol. Cell. Biol. 26, 4701- 4711 (2006).

36. Howe, L. R. Inflammation and breast cancer

Cyclooxygenase/prostaglandin signaling and breast cancer. Breast Cancer Res. 9, 210- 218 (2007).

37. Howe, L. R., Chang, S. H., Tolle, K. C., Dillon, R., Young, L. J. \& Cardiff, R. D. HER2/neuinduced mammary tumorigenesis and angiogenesis are reduced in cyclooxygenase-2 knockout mice. Cancer Res. 65,10113- 10119 (2005).

38. Harris, R. E., Beebe, J. \& Schwartzbaum, J. A. chemoprevention of breast cancer by cyclooxygenase and lipoxygenase inhibitors. World Acad. Sci. J. 2, 14-18 (2020).

39. Simpson, E. R., Mahendroo, M. S., Means, G. D., Kilgore, M. W., Hinshelwood, M. M. \& Graham-Lorence, S. Aromatase cytochrome P450, the enzyme responsible for estrogen biosynthesis. Endocr. Rev. 15, 342- 355 (1994).

40. Ferretti G., Bria E., Giannarelli D., Felici A., Papaldo P. \& Fabi A. Second- and third-generation aromatase inhibitors as first-line endocrine therapy in postmenopausal metastatic breast cancer patients: a pooled analysis of the randomised trials. Br. J. Cancer. 94,1789- 1796 (2006).

41. Chen, D., Song, M., Mohamad, O. \& Yu, S. P. Inhibition of $\mathrm{Na}^{+} / \mathrm{K}^{+}$-ATPase induces hybrid cell death and enhanced sensitivity to chemotherapy in human glioblastoma cells. Chen et al. BMC Cancer. 14, 716- 731 (2014) .

42. Zhang, S., Malmersjo, S., Li, J., Ando, H., Aizman, O. \& Uhlen, P. Distinct role of the N-terminal tail of the Na, K-ATPase catalytic subunit as a signal transducer. J. Biol. Chem. 281, 21954- 21962 (2006).

43. Yu, SP. Regulation and critical role of potassium homeostasis in apoptosis. Prog. Neurobiol. 70, $363-386$ (2003).

44. Onland-Moret, N. C., Kaaks, R., Van Noord, P. A., Rinaldi, S., Key, T. \& Grobbee, D. E. Urinary endogenous sex hormone levels and the risk of postmenopausal breast cancer. Br. J. Cancer. 88, 1394- 1399 (2003).

45. Yager, J. D. \& Davidson, N. E. Mechanisms of disease estrogen carcinogenesis in breast cancer. N. Engl. J. Med. 354, 270-282 (2006).

46. Liu, S., Chia, S. K., Mehl, E., Leung, S., Rajput, A. \& Cheang, M. C. U. Progesterone receptor is a significant factor associated with clinical outcomes and effect of adjuvant tamoxifen therapy in breast cancer patients. Breast Cancer Res. Treat. 119, 53- 61 (2010).

47. Yerma, A. K., Johnson, J. A., Gould, M. N. \& Tanner, M. A. Inhibition of 7,12-dimethylbenz (a) anthracene- and Nnitrosomethylurea-induced rat mammary cancer by dietary flavonol quercetin. Cancer Rese; 48: 5754- 5758 (1988).

48. Van Pelt, L. F. Ketamine and xylazine for surgical anesthesia in rats. J. Am. Vet. Med. Assoc. 171, $842-844$ (1977).

49. Lai, H. \& Singh, N. P. Oral artemisinin prevents and delays the development of 7,12-dimethylbenz[a]anthracene (DMBA)-induced breast cancer in the rat. Cancer Lett. 231, 43- 48 (2006).

50. Henry, R. J. Clinical chemistry. Harper and Row, New York, 1964; p 181(1964)

51. Doumas, B. T., Waston, W. A. \& Biggs, H. G. Albumin standards and the measurement of serum albumin with bromocresol green. Clin. Chem. Acta. 31, 87- 96 (1971). 
52. Reitman, S. \& Frankel, S. Determination of serum glutamate oxaloacetate and glutamate pyruvate transaminases. Am. J. Clin. Pathol. 28, 56- 60 (1957).

53. Reinhold, J. G. In: Reiner M (ed) Standard methods of clinical chemistry, vol I. Academic, New York, p 88 (1953).

54. Tabacco, A., Meiathini, F., Moda, E. \& Tarli, P. Simplified enzymic/colorimetric serum urea nitrogen determination. Clin. Chem. 25, 336- 337 (1979).

55. Gochman, N. \& Schmitz, J. M. Automated determination of uric acid with use of a uricase-peroxidase system. Clin. Chem. 17, 1154- 1159 (1971).

56. Faulkner, W. R. \& King, J. W. Renal function. In: Teitz N (ed) Fundamentals of clinical chemistry. W.B. Saunders, Philadelphia, pp 975- 1014 (1976).

57. Allain, C. C, Poon, L. S, Chan, C. S, Richand, W. \& Paul, C. F. Enzymatic determination of total cholesterol. Clin. Chem. 20, 470- 474 (1974).

58. Naito, H. K. \& Kaplan, A. Q. High-density lipoprotein (HDL) cholesterol. In: Pesce AJ, Kaplan LA (eds) Methods in clinical chemistry. C.V. Mosby, St. Louis, p 437, pp 1207- 1213 (1984).

59. Fossati, P. \& Prencipe, L. Enzymatic determination of triglycerides. Clin. Chem. 28: 2077 (1982) .

60. Friedewald, W. T., Levy, R. I. \& Fredrickson, D. S. Estimation of the concentration of low-density lipoprotein cholesterol in plasma, without use of the preparative ultracentrifuge. Clin. Chem. 18, 499- 502 (1972).

61. Kikuchi, H. H, Onodera, N,. Matsubara, S., Yasuda, E., Chonan, O., Takahash, R. \& Ishikawa F. Effect of soy milk and bifidobacterium fermented soy milk on lipid metabolism in aged ovariectomized rats. Biotechnol. Biochem. 62, 1688- 1692 (1998).

62. Griffith, O. W. Determination of glutathione and glutathione disulfide using glutathione reductase and 2-vinyl pyridine. Anal. Biochem. 106, 207- 212 (1980).

63. Goldberg, D. M. \& Spooner R. J. In: Bargemen HV (ed) Methods of enzymatic analysis. Verla.g Chemie Weinheim 3, 258- 265 (1983).

64. Paglia, D. E. \& Valentine, W. N. Studies on the quantitative and qualitative characterization of erythrocyte glutathione peroxidase. J. Lab. Clin. Med. 70, 158- 169 (1967).

65. Habig, W. H., Pabst, M. I. \& Jacoby, W. B. Glutathione-S-transferase. J. Biol. Chem. 249, 7130- 7139 (1974).

66. Beers, R. F. \& Sizer, I. W. A spectrophotometric method for measuring the breakdown of $\mathrm{H}_{2} \mathrm{O}_{2}$ by catalase. J Biol Chem. 195, 133- 140 (1952).

67. Fridovich, I. Superoxide dismutases. Adv. Enzymol. Relat. Areas. J. Mo.I Biol. 41, 35- 97 (1974).

68. Ohkawa, H., Ohishi, N. \& Yagi, K.. Assay for lipid peroxides in animal tissues by thiobarbituric acid reaction. Anal. Biochem. 95: 351- 358 (1979) .

69. Drury, R. A. B. \& Wallington, F. A. Corleton's histological technique. 4th Ed. Oxford, New York, Toronto, Oxford University Press (1980).

\section{Tables}

Table 1: The protective and therapeutic effect of BEPS on vital organs of DMBA- induced breast cancer in female rats. 
Parameters

Organ's weight $(\mathrm{g} / \mathrm{100g})$

\begin{tabular}{|c|c|c|c|c|c|c|c|}
\hline Groups & Liver & Kidney & Spleen & Lung & Heart & Brain & Total breast \\
\hline $\begin{array}{l}\text { Negative } \\
\text { control }\end{array}$ & $2.88 \pm 0.08$ & $1.01 \pm 0.02^{c}$ & $0.39 \pm 0.03^{b}$ & $0.80 \pm 0.04^{\mathrm{e}}$ & $0.44 \pm 0.02^{h}$ & $0.98 \pm 0.05^{\mathrm{u}}$ & $2.27 \pm 0.22^{t}$ \\
\hline $\begin{array}{l}\text { DMBA } \\
\text { control }\end{array}$ & $4.69 \pm 0.15^{*}$ & $0.71 \pm 0.04^{\star}$ & $0.95 \pm 0.04^{*}$ & $0.66 \pm 0.03^{*}$ & $0.52 \pm 0.04^{*}$ & $1.17 \pm 0.0^{*}$ & $10.56 \pm 0.46^{*}$ \\
\hline $\begin{array}{l}\text { BEPS } \\
\text { control }\end{array}$ & $3.06 \pm 0.16^{a}$ & $1.01 \pm 0.08^{c}$ & $0.41 \pm 0.03^{b}$ & $0.81 \pm 0.05^{\mathrm{e}}$ & $0.43 \pm 0.02^{h}$ & $1.00 \pm 0.14^{\mathrm{u}}$ & $2.26 \pm 0.20^{t}$ \\
\hline $\begin{array}{l}\text { BEPS pre- } \\
\text { treatment }\end{array}$ & $3.09 \pm 0.18^{a}$ & $1.19 \pm 0.08^{c}$ & $0.74 \pm 0.05^{*}$ & $\begin{array}{l}0.72 \pm 0.02^{*} \\
d\end{array}$ & $0.39 \pm 0.02^{\star}$ & $1.03 \pm 0.04^{\star}$ & $5.12 \pm 0.16^{*}$ \\
\hline $\begin{array}{l}\text { BEPS post- } \\
\text { treatment }\end{array}$ & ${ }_{*}^{3.45 \pm 0.13^{a}}$ & $0.98 \pm 0.03^{c}$ & $0.76 \pm 0.03^{*}$ & $0.75 \pm 0.03^{*}$ & $0.43 \pm 0.03^{h}$ & $1.03 \pm 0.08^{\star}$ & $6.11 \pm 0.09^{\star}$ \\
\hline
\end{tabular}

The presented data are mean of 10 replicates \pm SE. Data were analyzed using ANOVA one-way followed with Dunnett $t-$ tests as post hoc for multiple comparisons. Dunnett t-tests treat one group as a control and compare all other groups against it. *means the difference is significant at the 0.05 level compared to the negative control. $P<0.05$.

Table 2: The protective and therapeutic effect of BEPS on liver functions in DMBA- induced breast cancer in female rats.

\begin{tabular}{|c|c|c|c|c|c|c|}
\hline $\begin{array}{l}\text { Parameters } \\
\text { Groups }\end{array}$ & $\begin{array}{l}\text { AST } \\
(\mathrm{U} / \mathrm{I})\end{array}$ & $\begin{array}{l}\text { ALT } \\
(\mathrm{U} / \mathrm{I})\end{array}$ & $\begin{array}{l}\text { Total } \\
\text { protein } \\
(\mathrm{mg} / \mathrm{dl})\end{array}$ & $\begin{array}{l}\text { Albumin } \\
(\mathrm{mg} / \mathrm{dl})\end{array}$ & $\begin{array}{l}\text { Globulin } \\
\text { (mg/ dl) }\end{array}$ & $\begin{array}{l}\text { GSH } \\
(\mathrm{mg} / \mathrm{dl})\end{array}$ \\
\hline Negative control & $69.45 \pm 2.90^{a}$ & $\begin{array}{l}26.89 \\
\pm 0.91^{c}\end{array}$ & $\begin{array}{l}7.89 \\
\pm 0.24 \mathrm{~m}\end{array}$ & $4.51 \pm 0.33$ & $4.38 \pm 0.07$ & $7.24 \pm 0.11^{\mathrm{s}}$ \\
\hline DMBA control & $\begin{array}{l}161.01 \\
\pm 1.00^{\star}\end{array}$ & $48.75 \pm 1.05^{\star}$ & $3.37 \pm 0.16^{*}$ & $2.18 \pm 0.15^{*}$ & $1.19 \pm 0.08^{\star \star}$ & $2.47 \pm 0.24^{\star \star}$ \\
\hline BEPS control & $69.47 \pm 1.25^{a}$ & $27.64 \pm 1.11^{c}$ & $7.83 \pm 0.22 \mathrm{~m}$ & $4.32 \pm 0.16$ & $3.81 \pm 0.16^{* b}$ & $7.79 \pm 0.41^{*}$ \\
\hline BEPS pre-treatment & $79.43 \pm 1.28^{* b}$ & $27.31 \pm 1.38^{c}$ & $7.27 \pm 0.63^{m}$ & $3.90 \pm 0.37^{\star} \mathrm{h}$ & $3.87 \pm 0.24^{\star b}$ & $6.33 \pm 0.27^{\star}$ \\
\hline BEPS post-treatment & $74.12 \pm 1.54^{\star b}$ & $30.55 \pm 1.18^{*}$ & $7.57 \pm 0.22^{*}$ & $3.90 \pm 0.29^{*} h$ & $3.37 \pm 0.15^{\star}$ & $7.46 \pm 0.34^{s}$ \\
\hline
\end{tabular}

The presented data are mean of 10 replicates \pm SE. Data were analyzed using ANOVA one-way followed with Dunnett $t-$ tests as post hoc for multiple comparisons. Dunnett t-tests treat one group as a control and compare all other groups against it. *The mean difference is significant at the 0.05 level compared to the negative control, whereas groups with the same letter have insignificant differences $(P \leq 0.05)$.

Table 3: The protective and therapeutic effect of BEPS on Kidney functions in DMBA-induced breast cancer in female rats. 


\begin{tabular}{|c|c|c|c|}
\hline $\begin{array}{l}\text { Parameter } \\
\text { Group }\end{array}$ & $\begin{array}{l}\text { Creatinine } \\
(\mathrm{mg} / \mathrm{dl})\end{array}$ & $\begin{array}{l}\text { Uric acid } \\
\text { (mg/dl) }\end{array}$ & $\begin{array}{l}\text { Urea } \\
(\mathrm{mg} / \mathrm{dl})\end{array}$ \\
\hline Negative control & $3.23 \pm 0.19^{a}$ & $2.43 \pm 0.16^{b}$ & $9.87 \pm 0.24^{q}$ \\
\hline DMBA control & $4.06 \pm 0.16^{*}$ & $3.07 \pm 0.17^{\star}$ & $12.43 \pm 0.47^{\prime}$ \\
\hline BEPS control & $3.29 \pm 0.12^{a}$ & $2.59 \pm 0.15^{b}$ & $9.87 \pm 0.41^{\mathrm{q}}$ \\
\hline BEPS pre-treatment & $3.77 \pm 0.21^{\star}$ & $3.57 \pm 0.13^{\star} n$ & $8.25 \pm 0.20^{*}$ \\
\hline BEPS post-treatment & $3.67 \pm 0.13^{*}$ & $3.42 \pm 0.11^{\star n}$ & $8.94 \pm 0.12^{\star}$ \\
\hline
\end{tabular}

The presented data are mean of 10 replicates \pm SE. Data were analyzed using ANOVA one-way followed with Dunnett ttests as post hoc for multiple comparisons. Dunnett t-tests treat one group as a control and compare all other groups against it. *The mean difference is significant at the 0.05 level compared to the negative control. Groups with the same letter showed insignificant differences $(P \leq 0.05)$.

Table (4): Impact of BEPS on serum lipid, in DMBA induced breast cancer in female rat

\begin{tabular}{|c|c|c|c|c|c|c|}
\hline $\begin{array}{l}\text { Biomarkers } \\
\text { Groups }\end{array}$ & $\begin{array}{l}\text { TG } \\
\mathrm{mg} / \mathrm{dL} .\end{array}$ & $\begin{array}{l}\text { TC } \\
\mathrm{mg} / \mathrm{dL} .\end{array}$ & $\begin{array}{l}\mathrm{HDL}-\mathrm{C} \\
\mathrm{mg} / \mathrm{dL} .\end{array}$ & $\begin{array}{l}\text { VLDL-C } \\
\mathrm{mg} / \mathrm{dL} .\end{array}$ & $\begin{array}{l}\text { LDL-C } \\
\text { mg/dL. }\end{array}$ & $\begin{array}{l}\text { RR } \\
\%\end{array}$ \\
\hline Negative control & $85.59 \pm 2.58^{a}$ & $66.89 \pm 2.02^{b}$ & $43.00 \pm 2.08^{d}$ & $17.12 \pm 0.63^{g}$ & $6.77 \pm 2.40^{y}$ & $0.16 \pm 0.07^{h}$ \\
\hline DMBA control & $161.01 \pm 5.89^{*}$ & $185.35 \pm 1.04^{*}$ & $29.38 \pm 0.88^{*}$ & $32.20 \pm 0.9 .6^{*}$ & $123.76 \pm 1.32^{*}$ & $4.22 \pm 0.17^{*}$ \\
\hline BEPS control & $81.10 \pm 3.79^{\star}$ & $67.27 \pm 5.71^{b}$ & $44.02 \pm 2.02^{d}$ & $16.22 \pm 0.76^{g}$ & $7.03 \pm 046^{y}$ & $0.16 \pm 0.02^{h}$ \\
\hline $\begin{array}{l}\text { BEPS pre- } \\
\text { treatment }\end{array}$ & $83.67 \pm 1.93^{a}$ & $71.25 \pm 1.59^{*}$ & $43.27 \pm 4.54^{d}$ & $16.13 \pm 0.39 \mathrm{~g}$ & $11.84 \pm 1.05^{*}$ & $0.28 \pm 0.05^{*}$ \\
\hline $\begin{array}{l}\text { BEPS post- } \\
\text { treatment }\end{array}$ & $85.28 \pm 3.27^{a}$ & $67.18 \pm 2.56^{b}$ & $43.95 \pm 0.05^{d}$ & $15.06 \pm 0.05^{\star}$ & $8.170 \pm 0.38^{*}$ & $0.19 \pm 0.03^{*}$ \\
\hline
\end{tabular}

The presented data are mean of 10 replicates \pm SE. Data were analyzed using ANOVA one-way followed with Dunnett ttests as post hoc for multiple comparisons. Dunnett t-tests treat one group as a control and compare all other groups against it. *The mean difference is significant at the 0.05 level compared to the negative control. Similar letters mean an insignificant difference between them. $P \leq 0.05$.

Table (5): The effect of BEPS on breast tumor characterization.

\begin{tabular}{|llll|}
\hline \multicolumn{1}{|c}{ Group } & DMBA group & pre-treatment group & Post treated group \\
\hline Parameter & & & \\
\hline Average \% of rat body weight gain & $131.56 \pm 1.21$ & $85.71 \pm 1.00^{\mathrm{a}^{*}}$ & $92.56 \pm 1.04^{\mathrm{a}}$ \\
\hline No. of cancers developed & $13.00 \pm 0.98$ & $9.00 \pm 0.82^{*}$ & $7.00 \pm 0.61^{*}$ \\
\hline Weight of cancer mass $\mathbf{( g )}$ & $1.11 \pm 0.12$ & $0.71 \pm 0.11^{*}$ & $0.52 \pm 0.13^{*}$ \\
\hline Volume of cancer mass $\left(\mathrm{cm}^{3}\right)$ & $1.28 \pm 0.09$ & $0.82 \pm 0.05^{*}$ & $0.60 \pm 0.08^{*}$ \\
\hline
\end{tabular}


The presented data are mean of 10 replicates \pm SE. ANOVA one-way followed with Duncan t-tests as post hoc for multiple comparisons. Groups with the same letter indicate insignificant differences in the same parameter $(P 0.05)$. The appearance of * means significant as compared to the DMBA group.

\section{Figures}



Figure 1

The protective and therapeutic effect of BEPS on lipid peroxidation of DMBA- induced breast cancer in female rats.

The presented data are mean of 10 replicates \pm SE. ANOVA one-way followed with Duncan t-tests as post hoc for multiple comparisons. Groups having the same letter in the same columns are not significantly different from each other, while those having different letters are significantly different from each other. They were occurring of * means a significant difference compared to the cancer control group. $P \leq 0.05$, MDA; malondialdehyde the end product of the lipid peroxidation. 


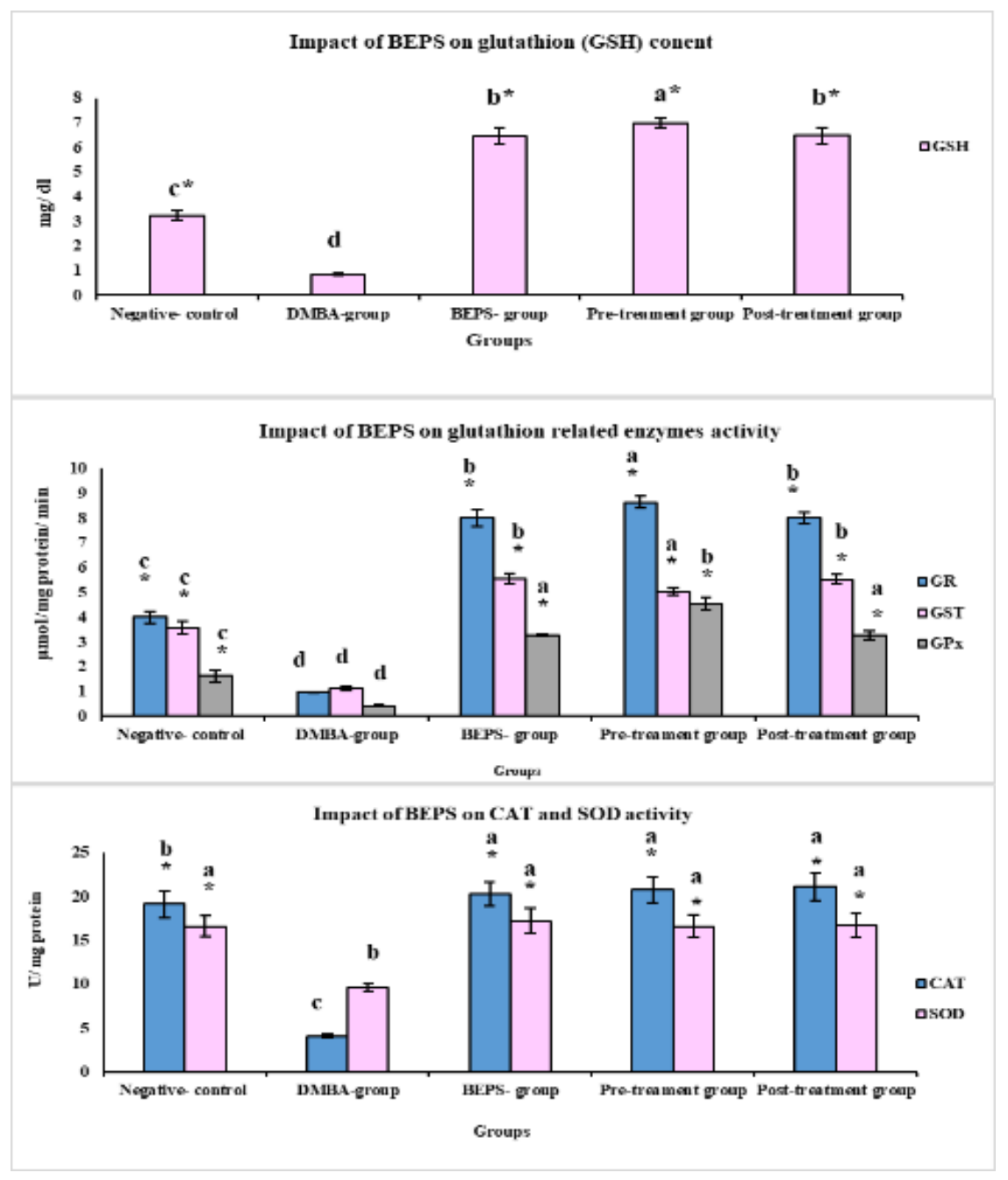

Figure 2

Efficacy of BEPS protective and therapeutic administration on antioxidant status of DMBA-induced breast cancer in female rats.

The presented data are mean of 10 replicates \pm SE. ANOVA one-way followed with Duncan t-tests as post hoc for multiple comparisons. Groups having the same letter in the same columns are not significantly different from each other, while those having different letters are significantly different from each other. Occurring of * means a significant difference compared to the cancer control group. $P \leq 0.05$. GSH; glutathione L. reduced, GR; glutathione reductase, GST; glutathione S transferase; GPx glutathione peroxidase, CAT; catalase, and SOD; superoxide dismutase. 


\section{Impact of BEPS on inflammation biomarkers}

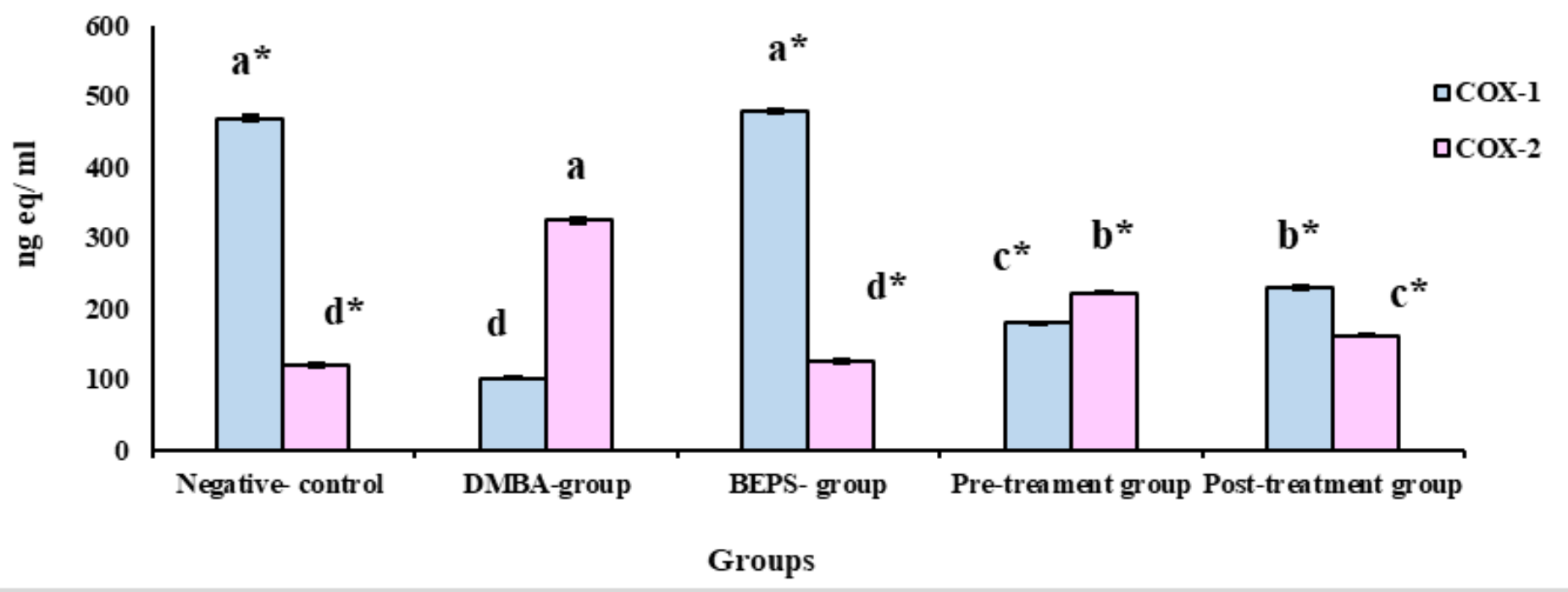

Figure 3

The protective and therapeutic effect of BEPS on inflammation rate-limiting enzymes of DMBA-induced breast cancer in female rats.

The presented data are mean of 10 replicates \pm SE. ANOVA one-way followed with Duncan t-tests as post hoc for multiple comparisons. Groups having the same letter in the same columns are not significantly different from each other, while those having different letters are significantly different from each other. Occurring of * means a significant difference compared to the cancer control group. $P \leq 0.05$. COX-1; cyclooxygenase 1 , and COX-2; cyclooxygenase- 2 . 

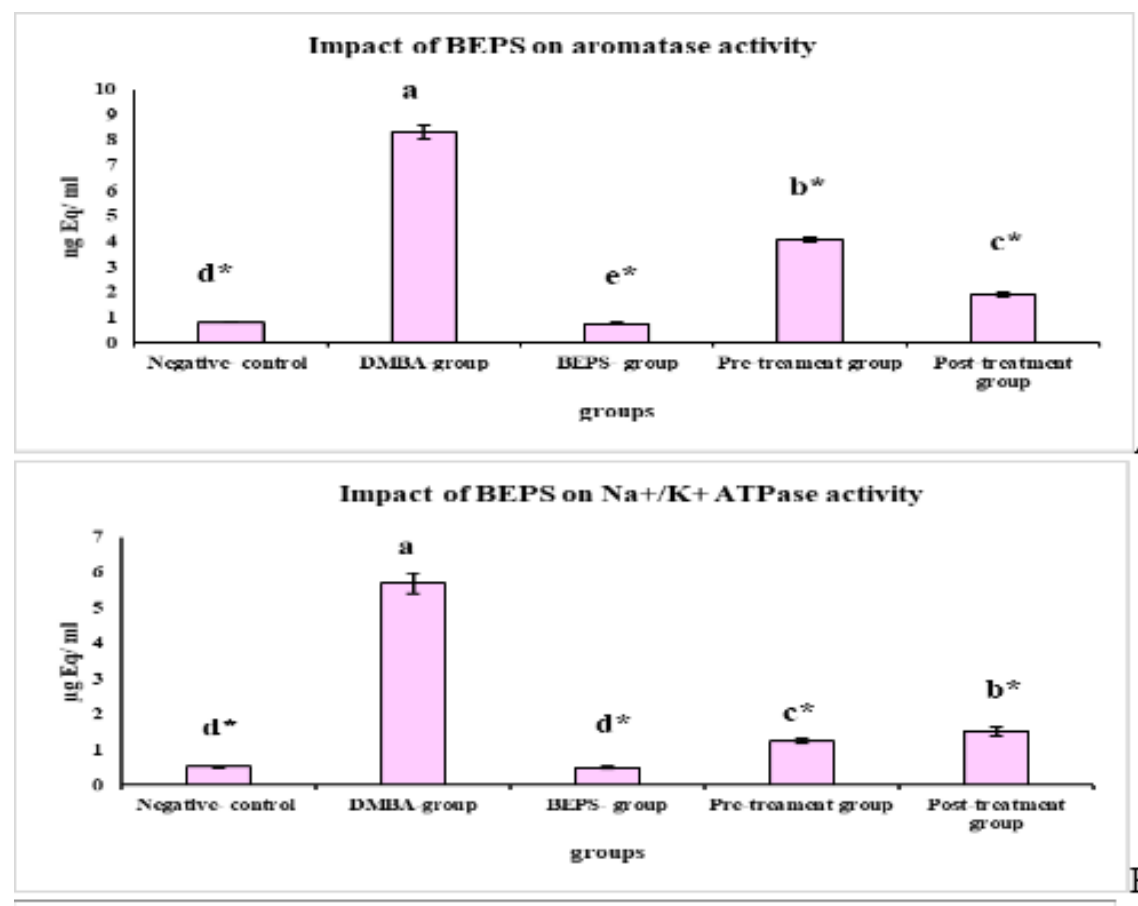

A

B

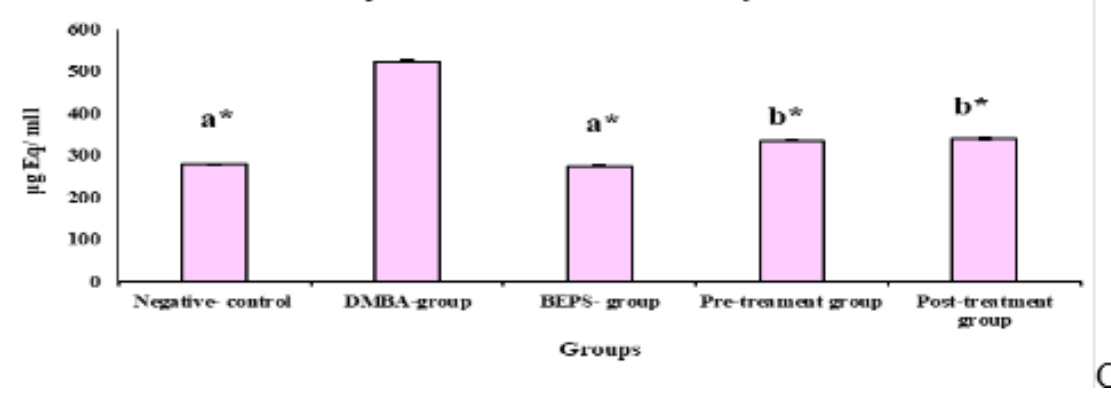

Figure 4

The protective and therapeutic effect of EBAP on Cancer growth rate-limiting enzymes; aromatase (A), $\mathrm{Na}^{+} / \mathrm{K}^{+} \mathrm{ATPase}$ activity (B) and cancer biomarkers; CEA (C) of DMBA- induced breast cancer in female rats.

The presented data are mean of 10 replicates \pm SE. ANOVA one-way followed with Duncan t-tests as post hoc for multiple comparisons. Groups having the same letter are not significantly different from each other, while those having different letters are significantly different from each other. $P \leq 0.05$. Carcinoembryonic antigen (CEA). Occurring of * means a significant difference compared to the cancer control group. $P \leq 0.05$ 


\section{Impact of BEPS on estrogen and progesterone (ng/ ml)}

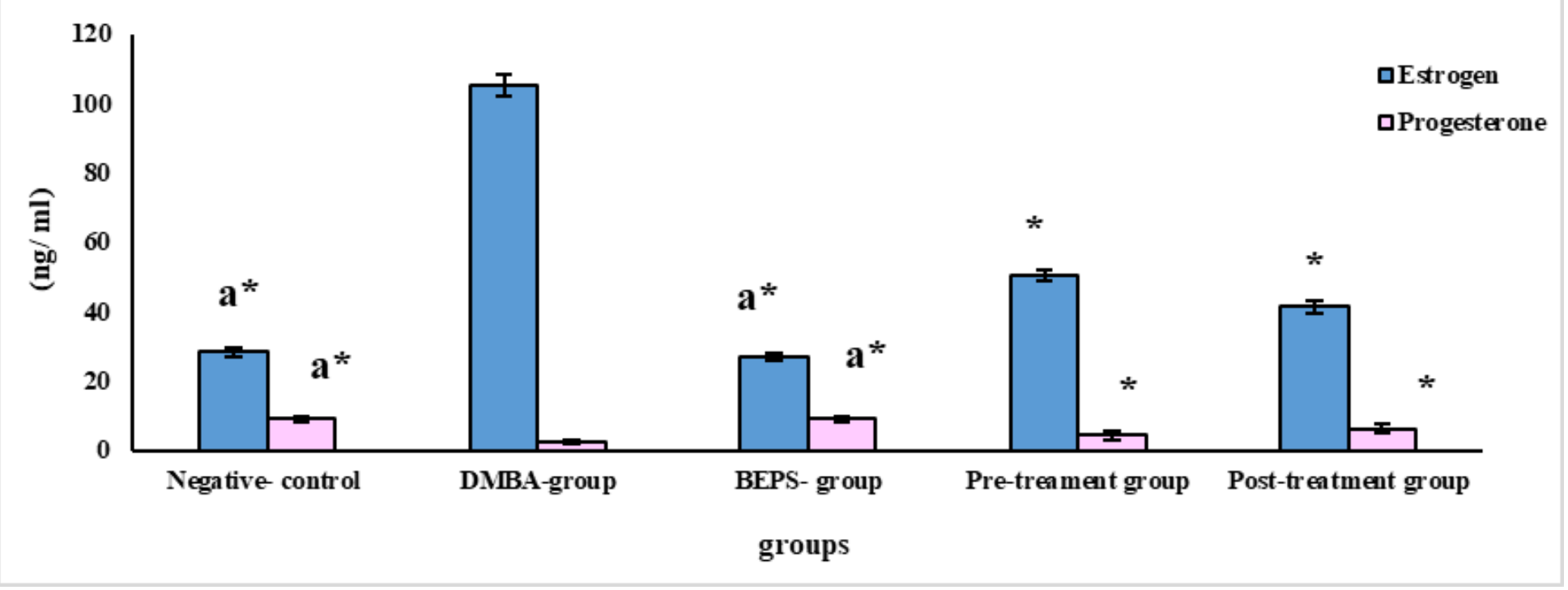

Figure 5

The protective and therapeutic effect of BEPS on rat sex hormones of DMBA-induced breast in female rats.

The presented data are mean of 20 replicates \pm SD. Data were analyzed using ANOVA one-way followed with post hoc for multiple comparisons. The appearance of * means the significant difference between groups and cancer control. In contrast, the appearance of letters means an insignificant difference between groups with the same letter compared to cancer controls. 

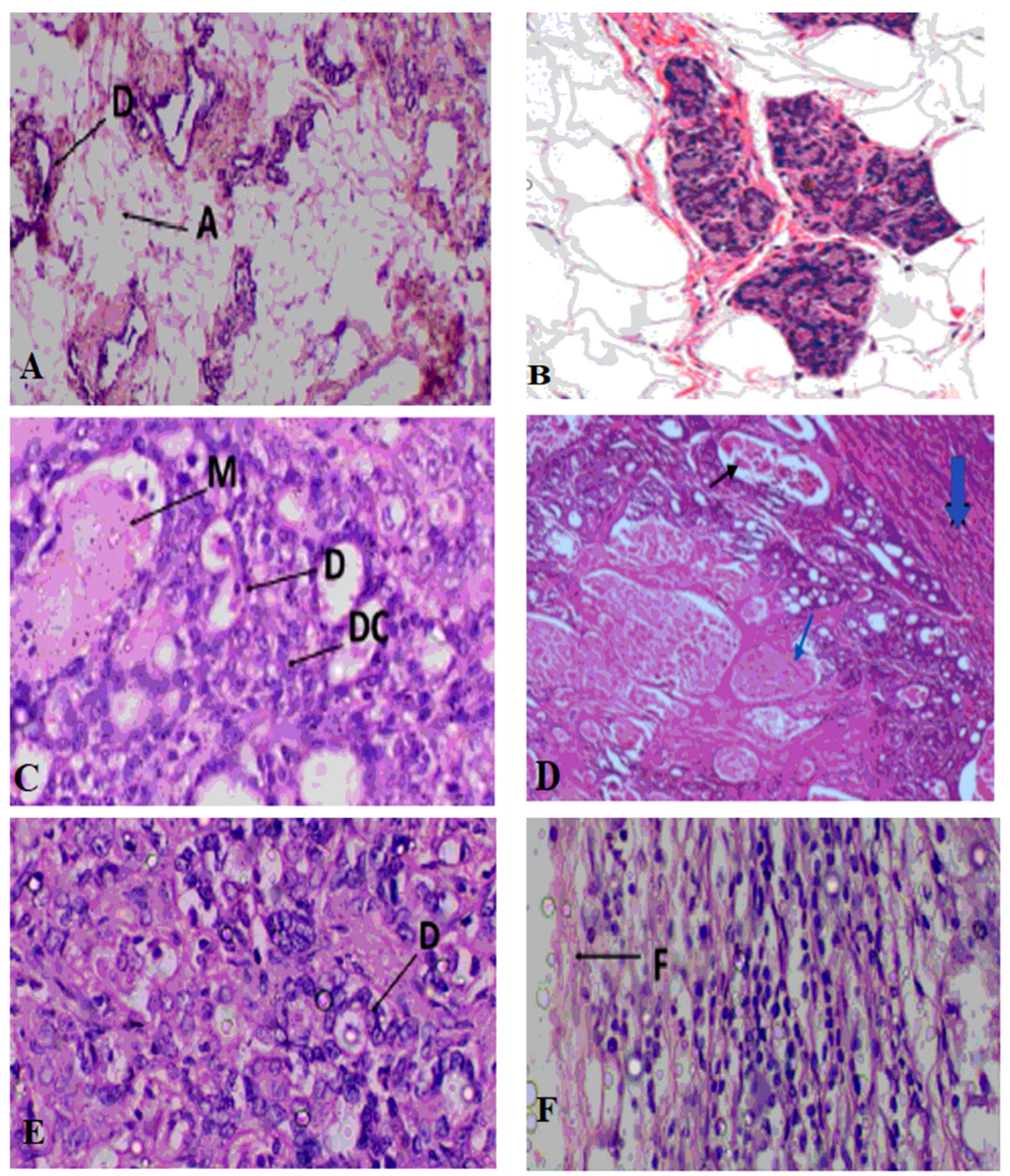

\section{Figure 6}

Microphotograph using hematoxylin and eosin in control rats is appeared in sections, (A) Mammary section of the negative control, which showed rat mammary tissue in a normal arrangement of adipocytes (A) and duct (D) $(\times 500)$. (B) Mammary section of the BEPS-control rats shows normal ducts, epithelia, and stroma. (C) Mammary tissue section of DMBA-treated group rat shows dedifferentiated cells (DC) with the presence of mucin (M) in the ductal (D) lumen with discontinuous basement membrane ( $\times 500)$. (D) Mammary tissue section of DMBA-treated group rat shows necrosis in vast areas, and tumor breakdown exhibits tumor cells in high proliferation, surrounded by residual viable proliferating malignant cells (black arrow). Note the presence of dead cells (thin blue arrow) while the neoplastic cells invasive feature showed in bold blue arrow. (H\&E X 200). (E) The mammary tissue of the pre-treatment group section, whereas the $(F)$ The mammary tissue of the post-treated group rat section presents. It could appear that, although the ducts (D) basement membrane is discontinuous, there is the absence of mucin and any other foreign substances. At the same 
time, it is covered with a thick mass of fibrous connective tissues with a post-treatment of polysaccharide, as shown in section $(F)(\times 500)$. 